\title{
AS POLIITICAS MACROPRUDENCIAIS E A CONCORRÊNCIA BANCÁRIA ENTRE 2009 E 2016
}

\author{
Marcelo H. Shinkoda * \\ Marcelo José Braga ${ }^{\dagger}$
}

\begin{abstract}
Resumo
O objetivo deste trabalho foi analisar se as políticas macroprudenciais/concorrenciais editadas entre 2009 e 2016 afetaram direta ou indiretamente a conduta concorrencial das instituições financeiras. Para isso utilizou-se a estatística H de Panzar e Rosse. Os dados foram constituídos por um painel com 44 instituições bancárias que atuaram no Brasil no período. Os resultados indicaram que a conduta das instituições financeiras foi, entre 2009 e 2013, de um monopólio, passando a uma conduta neutra entre 2014 e 2015 e, a partir de então, uma concorrência monopolística. Concluiu-se que a política de portabilidade do crédito (editada em dezembro de 2013) foi a que teve impacto de neutralidade sobre a competição das instituições financeiras, enquanto que a exigibilidade de Basileia III a partir de 2015 efetivou a conduta competitiva do setor.
\end{abstract}

Palavras-chave: competição bancária; bancos; estatística H.

\begin{abstract}
The objective of this study was to analyze whether macroprudential/competitive policies published between 2009 and 2016 directly or indirectly affected the competitive behavior of financial institutions. For this purpose, $\mathrm{H}$ statistic, by Panzar e Rosse, was used. The data were constituted by a panel with 44 banking institutions that acted in Brazil in the period. The results indicated that the conduct of financial institutions was, from 2009 to 2013, a monopoly, became a neutral conduct between 2014 and 2015 and thereafter a monopolistic competition. It was concluded that the credit portability policy (published in December 2013) was the one that had an impact of neutrality on the competition of the financial institutions, whereas the Basel III from 2015 on made the competitive behavior of sector.
\end{abstract}

Keywords: bank competition; banks; H-statistic.

JEL classification: L13, G21.

DOI: http://dx.doi .org/10.11606/1980-5330/ea 146483

\footnotetext{
* Universidade Federal de Viçosa. E-mail:marcelo.shinkoda@ufv.br

† Universidade Federal de Viçosa. E-mail: mjbraga@ufv.br
} 


\section{Introdução}

As preocupações de políticas econômicas/monetárias do governo federal têm se centralizado no controle da inflação. A equipe econômica do Ministério Fazenda, ao longo do período de 2009 a 2016, adotou medidas macroprudenciais ${ }^{1}$ que, em teoria, combatem a inflação por meio de três canais monetários: o câmbio, através da concorrência dos preços internacionais; as taxas de juros, que impactam diretamente os investimentos através de um corte na demanda; e, por fim, o canal de crédito - por meio da elevação do compulsório.

As medidas macroprudenciais que afetam o canal de crédito muitas vezes são usadas como alternativa à variação das taxas de juros e podem ter impactos diretos sobre a estrutura concorrencial das instituições financeiras. $\mathrm{O}$ aumento do recolhimento compulsório, por exemplo, mesmo que remunerado à taxa SELIC ${ }^{2}$ (taxa referencial do Sistema Especial de Liquidação e de Custódia), permeia a rentabilidade dos bancos, já que o a diferença entre esta taxa e àquela aplicada no mercado de empréstimos ${ }^{3}$ é relativamente elevada (Figura 8). Assim, a prática desta política pode ser avaliada com certo ceticismo pelas instituições financeiras, já que, por determinação exógena, esta medida substituiria as rentabilidades dos recursos acumulados e provocaria uma reação em cadeia, que se inicia com o aumento da alavancagem dos banqueiros e termina com maiores taxas ao consumidor final (ver (Gertler \& Karadi 2011)).

Logo, sob um olhar concorrencial, essas medidas podem modificar a conduta das instituições financeiras, as quais, em um mercado oligopolizado ${ }^{4}$ (Tabela 1), podem definir estratégias parecidas, configurando um conluio tácito, de forma a equilibrar as ações do governo. Desde as reformulações da década de 1990 no setor financeiro (PROER, PROES e Plano Real), os bancos públicos, frente às ações dos bancos privados, adotam estratégias anticíclicas ${ }^{5}$. No entanto, o relatório do DIEESE (2017) sobre o mercado bancário de 2016 aponta para o fim das ações anticíclicas das instituições financeiras públicas, que passaram também a restringir o crédito ao setor privado/consumo.

Nesse sentido, o presente artigo propõe analisar a conduta das instituições financeiras de varejo após a implementação das políticas macroprudenciais ao longo do período de 2009 a 2016. O foco é identificar quais eram as estratégias competitivas dos bancos no momento da implementação dessas políticas e avaliar sua evolução ao longo do tempo. As hipóteses assumidas são: os bancos públicos exerceram o poder de monopólio no período analisado; as políticas macroprudenciais interferem no mercado interfinanceiro, alteram os

\footnotetext{
${ }^{1}$ Medidas macroprudenciais são ações complementares que fortalecem o sistema financeiro protegendo-o contra o risco sistêmico (Poutineau \& Vermandel (2017), p.4). Através destas medidas as autoridades monetárias administram os efeitos das crises financeiras e promovem a estabilidade de preços. No período, o principal foco foi a implementação da Basileia III.

${ }^{2}$ São remunerados os compulsórios dos depósitos a prazo e da poupança. Os primeiros são remunerados mediante a taxa Selic enquanto que o segundo é remunerado à taxa da poupança (Bacen 2011). O compulsório sobre os depósitos a vista não é remunerado.

${ }^{3}$ Não necessariamente os recursos captados pelos bancos são aplicados no mercado de empréstimos, mas a taxa cobrada no mercado de empréstimos é uma boa proxy por representar, em parte, o custo de oportunidade dos bancos.

${ }^{4}$ Mercado cujo índice de concentração CR4 é superior à 40 é definido como oligopólio (Martin 2010)

${ }^{5}$ Para mais detalhes sobre a concorrência entre bancos públicos e bancos privados ver Rocha (2001), Micco \& Panizza (2006), Camargo (2009), Allen et al. (2013),Brei \& Schclarek (2015) e Torres (2016).
} 
Tabela 1: Razão de Concentração das Cinco Maiores Instituições Financeiras nos Segmentos de Empréstimos, Depósitos de Poupança e Depósitos a Prazo no período de 2009-2016

\begin{tabular}{ccccccccc}
\hline Segmentos & $\mathbf{2 0 0 9}$ & $\mathbf{2 0 1 0}$ & $\mathbf{2 0 1 1}$ & $\mathbf{2 0 1 2}$ & $\mathbf{2 0 1 3}$ & $\mathbf{2 0 1 4}$ & $\mathbf{2 0 1 5}$ & $\mathbf{2 0 1 6}$ \\
\hline ETD & 70 & 72 & 72 & 73 & 77 & 78 & 75 & 77 \\
Depósitos de Poupança & 94 & 94 & 95 & 94 & 96 & 96 & 94 & 95 \\
Depósitos a Prazo & 74 & 70 & 71 & 73 & 78 & 79 & 77 & 78 \\
\hline
\end{tabular}

Fonte: estatística a partir do ESTBAN (Estatística Bancária Mensal por Município) divulgada pelo Banco Central do Brasil (Bacen) (ETD significa Empréstimos e Títulos Descontados)

custos das instituições e, portanto, mudam a estratégia concorrencial entre os bancos.

Para avaliar as hipóteses assumidas, a análise foi realizada por meio da Estatística H Local. Inicialmente desenvolvido por Panzar \& Rosse (1987), este método tem sido amplamente aplicado, tanto para a análise do mercado bancário nacional (Lucinda 2010, Tabak et al. 2012, 2015), quanto para o mercado bancário internacional (Molyneux et al. 1994, 1996, Delis 2010). As análises da metodologia de Panzar e Rosse para o mercado brasileiro, tendem a convergir para uma concorrência monopolística. Porém, a persistência dos elevados spreads bancários e a própria concentração deste setor colocam em dúvida se essa é realmente a estratégia concorrencial das instituições financeiras de varejo.

Assim, este artigo contribui com a literatura ao apresentar a evolução das estratégias de cada um dos bancos de varejo ao longo do período proposto. Contribui também ao relacionar a evolução da estratégia média destes bancos com as políticas implementadas. A avaliação individual vai muito além da estimativa de $\mathrm{P} \& \mathrm{Z}$ na média proposta pelos demais artigos, pois alguns bancos podem atuar em conluio na média e outros na mediana (uma vez que a concentração bancária é assimétrica à direita nos principais segmentos no qual atuam - Tabela 1).

Para atingir tais objetivos, o experimento ideal requereria que todas as instituições financeiras estivessem sob a influência de somente uma política macroprudencial ou concorrencial por vez, de forma que a conduta captada pela Estatística $\mathrm{H}$, na média do período, apontasse um possível efeito causal entre a edição da política e a adoção de determinada conduta da indústria bancária. No entanto, essa não é a realidade vista ou praticada. Assim, visando superar essa deficiência, a Estatística $H$ também foi estimada localmente, a nível de cada banco, por mês, de modo que a análise é realizada comparando a evolução da Estatística H Local com a variação dos coeficientes das políticas macroprudenciais.

Ao contrário dos demais trabalhos empíricos que analisaram a indústria bancária brasileira trimestralmente, este trabalho utilizou dados mensais, em um painel balanceado ${ }^{6}$ com 44 instituições financeiras e 96 períodos de tempo. A análise de dados mensais reflete a estrutura concorrencial de curto prazo da elasticidade do preço dos fatores. A ampliação dos prazos para analises trimestrais/semestrais pode esconder a real conduta mensal dos bancos, pois pode permitir que os agentes reajustem seus custos de modo que a resposta da receita total ao preço dos fatores esteja concentrada na parte inelástica da

\footnotetext{
${ }^{6}$ Um painel desbalanceado é apresentado em anexo como medida de robustez.
} 
curva de demanda naquele momento. Outro fator que muitos trabalhos ignoram é a existência do mercado interfinanceiro, onde as instituições financeiras se inter-relacionam por meio de empréstimos para saldar suas posições no período sem precisar recorrer ao Banco Central do Brasil (Bacen). Assim, além da análise tradicional, esta pesquisa contribui ao apresentar a Estatística $\mathrm{H}$ considerando os meses como cluster e os diversos bancos como indivíduos se inter-relacionando dentro de cada cluster.

Os principais resultados deste artigo indicam que a conduta dos bancos de varejo foi, entre 2009 e 2013, de um monopólio, passou a ser uma concorrência monopolística somente a partir de 2014. Duas foram as políticas implementadas no final de 2013: a primeira foi a portabilidade do crédito bancário e a segunda foi o estabelecimento do acordo de Basileia III. Porém, a exigibilidade do Basileia III somente entrou em vigor a partir de janeiro de 2015. Logo, pode-se considerar que a política de portabilidade do crédito é a principal responsável por manter uma estratégia de equilíbrio neutra, enquanto que o Basileia III se torna responsável pela conduta de concorrência monopolística verificada partir de 2015.

O restante deste artigo é organizado da seguinte forma: a seção 2 apresenta um breve panorama do setor e as políticas implementadas no período que serão analisadas; a seção 3 é dedicada ao plano de fundo teórico (identificação); a seção 4 é apresentado o modelo analítico, os procedimentos econométricos e à descrição dos dados; seção 5 apresenta e discute os resultados. O artigo finaliza com as conclusões.

\section{Panorama do setor bancário frente às políticas macroprudenciais}

O período de 2009 a 2016 foi marcado por diversas intervenções no setor bancário, seja por meio indireto, através de políticas macroprudenciais, seja por meio direto com a intensificação das condutas anticíclicas dos bancos públicos (Banco do Brasil e Caixa Econômica Federal) frente à retração do crédito dos bancos privados. As políticas prudenciais e as intervenções diretas no mercado bancário são reflexos da crise econômica norte americana de 2008.

Após a crise, o governo federal brasileiro adotou algumas políticas de subsídios a setores-chave da economia (Graupen 2015). Alguns destes setores foram: construção civil, com subsídio às construtoras - em um esforço de manter os empreendimentos do que, na época, era o principal ramo da economia, a Caixa Econômica Federal (CEF) ampliou o saldo disponível de crédito para a casa própria e o governo federal reduziu o IPI referente à materiais de construção; setor automotivo e o setor denominado de "Linha Branca" - com o intuito de manter aquecido o consumo, estes setores também tiveram redução no IPI; e, por fim, o setor bancário - com uma redução no compulsório que serviu de injeção às instituições financeiras, que deram continuidade à redução das taxas de juros (iniciadas na primeira metade da década), acompanhando as taxas internacionais.

Todas essas ações surtiram efeito ainda em 2009, quando os principais índices macroeconômicos voltaram às condições pré-crise. Porém, as consequências dessas relações nos gastos do governo federal nos anos seguintes se tornaram preocupantes para as instituições financeiras. A partir dos dados do Banco Central do Brasil (Bacen), verifica-se que a dívida pública bruta em per- 
centual do Produto Interno Bruto (PIB) saiu de 53\% em janeiro de 2008 para aproximadamente $70 \%$ do PIB em dezembro de 2016, enquanto que a inadimplência do consumidor (Pessoa Física) passou a crescer à uma taxa média de 4,5\% ao mês entre março de 2011 e dezembro de 2016 (Figura 1).

Figura 1: Evolução da dívida pública (bruta e líquida) e da inadimplência do consumidor (Pessoa Física)

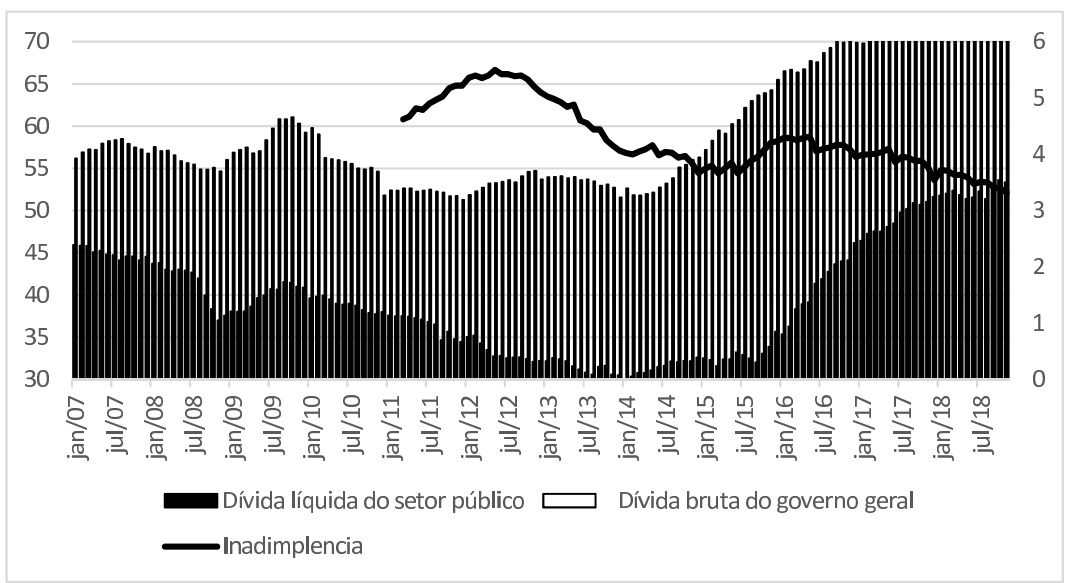

Fonte: Dados do Banco Central do Brasil.

Com a meta inflacionária variando entre 3\% e 6\%, já em 2010 o Banco Central do Brasil editou a Circular 3.513/2010, que alterou as taxas de recolhimento do compulsório e dos encaixes obrigatórios sobre os recursos a prazo. Essa medida prudencial serviu como uma sinalização de uma futura elevação da taxa Selic. No entanto, essa relação não parece ter sido satisfatória, pois a meta foi descumprida logo no ano seguinte e em 2014, 2015 e 2016 (Figura 2).

Figura 2: Evolução da inflação (\% a.a.)

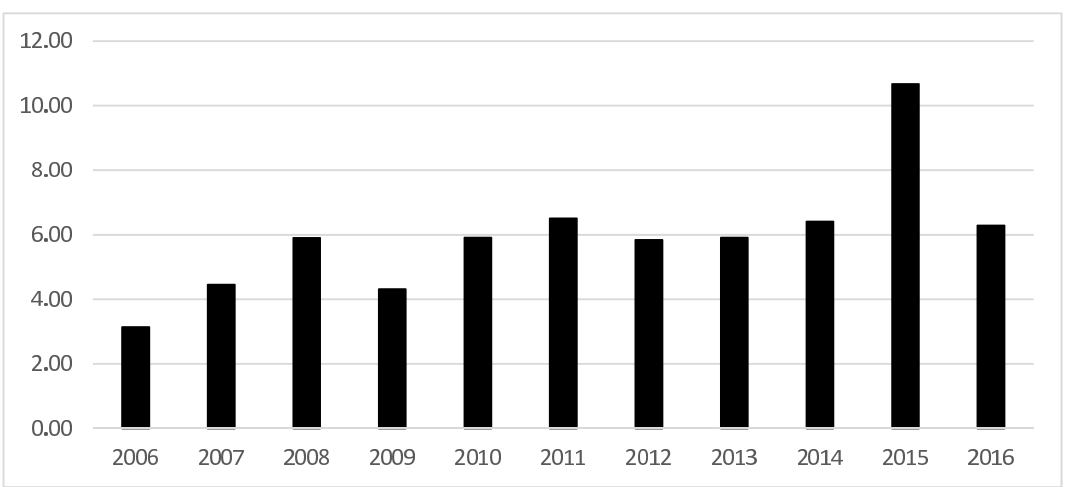

Fonte: Instituto Brasileiro de Geografia e Estatística/Sistema Nacional de Índices de Preços ao Consumidor (IBGE/SNIPC).

Em contrapartida, no sentido de manter o consumo aquecido, o governo federal intensificou, a partir de julho de 2012, as ações anticíclicas dos bancos públicos (ver Torres (2016)). Essa relação pressionou a redução das taxas de empréstimos dos bancos privados. No entanto, a conduta destes parece ter 
sido de financiamento daquela ação do governo pois, mesmo com a redução das taxas de juros, a parcela de mercado dos bancos privados no segmento de Empréstimos e Títulos Descontados reduziu ou permaneceu estável, enquanto que os bancos públicos, em conjunto, cresceram quase sete pontos percentuais (Tabela 2).

Tabela 2: Parcelas de mercado das cinco maiores instituições financeiras no segmento de Empréstimos e Títulos Descontados (\%) no período de 2009 a 2016

\begin{tabular}{|c|c|c|c|c|c|c|c|c|}
\hline Instituições Financeiras & 2009 & 2010 & 2011 & 2012 & 2013 & 2014 & 2015 & 2016 \\
\hline Banco do Brasil & 22 & 24 & 22 & 23 & 25 & 25 & 24 & 24 \\
\hline Bradesco & 15 & 14 & 14 & 13 & 13 & 13 & 13 & 13 \\
\hline Itaú-Unibanco & 14 & 14 & 14 & 13 & 11 & 13 & 12 & 12 \\
\hline Santander & 12 & 12 & 13 & 13 & 12 & 10 & 9 & 9 \\
\hline Caixa E. Federal & 7 & 8 & 9 & 11 & 16 & 18 & 17 & 19 \\
\hline
\end{tabular}

Em março de 2013, o Banco Central do Brasil passa a implementar um conjunto de documentos (Resoluções 4.192/2013 e 4.193/2013 e a circular 3.644/2013) que adequam o sistema financeiro nacional às resoluções dadas pela Basileia III (composta pelos documentos: "Global regulatory framework for more resilient banks and banking system" e "International framework for liquidity risk measurement, standards and monitoring") ${ }^{7}$. As principais inovações foram a criação do buffer anticíclico e dos buffers de conservação do capital. Os primeiros tendem a evitar as induções da Basileia II. Assim, na medida em que aumentam (reduzem) os riscos sistêmicos, os bancos deveriam reduzir (aumentar) os coeficientes de capital de forma a atenuar os impactos da oferta de crédito na economia. Os buffers de conservação serão acionados apenas quando o crescimento do crédito estiver acima de sua tendência e for "associado a um aumento dos riscos sistêmicos na economia" ANBIMA (2010). Segundo o Bacen (2018), desde a regulamentação em 2013, o Brasil ainda não experimentou a ativação oficial dos buffers de capital ${ }^{8}$. No entanto, no período de 2009 a 2016 o Brasil passou por diversas mudanças nas alíquotas dos recolhimentos do compulsório (Tabela 3).

Assim, as variações nessas alíquotas parecem delimitar o período de 2009 a 2016 como uma "estação" de teste, já que que, segundo Bacen (2013), os buffers somente poderiam ser ativados oficialmente a partir de janeiro de 2015. No entanto, a possibilidade da exigibilidade de um compulsório adicional sempre foi presente no Brasil, e suas variações no período ocorreram nos anos de 2009, 2010, 2012 e 2015 (Tabela 3) em todos os três segmentos (Depósitos à Vista, Depósitos a Prazo e Poupança).

\footnotetext{
${ }^{7}$ Para mais ver Bacen (2013).

${ }^{8}$ A circular do Banco Central do Brasil 3.769/2015 fixou em 0\% o adicional anticíclico de capital sobre riscos de crédito ao setor privado não bancário assumidos pelas instituições financeiras no Brasil (Bacen 2018).
} 
Tabela 3: Recolhimentos compulsórios - alíquotas entre 2009 e 2016 (\%, final do período)

\begin{tabular}{cccccccccc}
\hline Recursos - Origem & 2009 & $\mathbf{2 0 1 0}$ & $\mathbf{2 0 1 1}$ & $\mathbf{2 0 1 2}$ & $\mathbf{2 0 1 3}$ & $\mathbf{2 0 1 4}$ & $\mathbf{2 0 1 5}$ & $\mathbf{2 0 1 6}$ \\
\hline À Vista & 42 & 43 & 43 & 44 & 44 & 45 & 45 & 45 \\
Exigibilidade Adicional & 5 & 12 & 12 & 0 & 0 & 0 & 0 & 0 \\
\hline Depósito a Prazo & 13,5 & 20 & 20 & 20 & 20 & 20 & 25 & 25 \\
Exigibilidade Adicional & 4 & 12 & 12 & 11 & 11 & 11 & 11 & 11 \\
\hline Poupança Habitacional & 20 & 20 & 20 & 20 & 20 & 20 & 24,5 & 24,5 \\
Poupança Rural & 15 & 16 & 17 & 17 & 18 & 13 & 15,5 & 15,5 \\
Exigibilidade Adicional & 10 & 10 & 10 & 10 & 10 & 10 & 6 & 6 \\
\hline Fonte: estatística a partir do ESTBAN (Estatística Bancária Mensal por Município) \\
divulgada pelo Banco Central do Brasil (Bacen)
\end{tabular}

\section{Modelo Teórico}

O modelo de Panzar \& Rosse (1987), denominado P\&Z, quando aplicado para o setor bancário, será especificado a seguir.

Considere $y$ um vetor de variáveis de decisão que afetam a receita da firma, então:

$$
R_{i}=R^{*}(y, z)
$$

onde $y$ é o determinante exógeno da demanda e $z$ são os demais determinantes exógenos do custo que deslocam a função de receita da firma. Adicionalmente, assume-se que os custos das firmas dependem direta ou indiretamente de $y$. Então:

$$
C_{i}=C(y, w, t)
$$

onde $w$ é um vetor de $m$ fatores de preços que são exógenos para a firma e $t$ é um vetor de variáveis exógenas que deslocam a função de custo. Os vetores $t$ e $z$ podem ou não ter componentes comuns. Segundo Panzar \& Rosse (1987), é comum pensar que $y$ representa um vetor do nível do produto. Porém esta interpretação é sobretudo restritiva. O componente $y$ pode incluir preços, custos com propaganda, ou níveis de qualidade (que no caso do segmento bancário, seriam os empréstimos classificados de acordo com sua probabilidade de pagamento). Assim, o lucro da firma $i$ pode ser escrito como:

$$
\Pi_{i}=R_{i}-C_{i}=\Pi_{i}\left(y_{i}, z_{i}, w_{i}, t_{i}\right)
$$

Então, seja os seguintes problemas de otimização:

$$
\begin{gathered}
y_{i}{ }^{0}=\operatorname{argmax}_{y} \Pi_{i}\left(y_{i}, z_{i}, w_{i}, t_{i}\right) \\
y_{i}{ }^{1}=\operatorname{argmax}_{y} \Pi_{i}\left(y_{i}, z_{i},\left(1+h_{i}\right) w_{i}, t_{i}\right) ; \text { onde } h \geq 0
\end{gathered}
$$

Seja também as seguintes formas da receita que equivalem à forma reduzida da receita dos bancos, $R^{*}$ : 


$$
\begin{gathered}
R_{i}^{0}=R\left(y_{i}^{0}, z\right) \equiv R_{i}^{*}\left(z_{i}, w_{i}, t_{i}\right) \\
R_{i}^{1}=R\left(y_{i}^{1}, z_{i}\right) \equiv R_{i}^{*}\left(z_{i},\left(1+h_{i}\right) w_{i}, t_{i}\right)
\end{gathered}
$$

Logo, por definição:

$$
R_{i}^{1}-C_{i}\left(y_{i}^{1},\left(1+h_{i}\right) w_{i}, t_{i}\right) \geq R_{i}^{0}-C_{i}\left(y_{i}^{0},\left(1+h_{i}\right) w_{i}, t_{i}\right) .
$$

Uma vez que $C$ é linearmente homogênea em $w$, (8) pode ser escrita como:

$$
R_{i}^{1}-\left(1+h_{i}\right) C_{i}\left(y_{i}^{1}, w_{i}, t_{i}\right) \geq R_{i}^{0}-\left(1+h_{i}\right) C_{i}\left(y_{i}^{0}, w_{i}, t_{i}\right)
$$

Ao multiplicar ambos os lados de $(9)$ por $\left(1+h_{i}\right)$ e adicionar o resultado em (8) produz:

$$
-h_{i}\left(R_{i}^{1}-R_{i}^{0}\right) \geq 0
$$

Ao dividir ambos os lados de (10) por $-h_{i}^{2}$ e substituir $R_{i}^{1}$ e $R_{i}^{0}$ por suas equivalências (6) e (7), chega-se :

$$
\frac{\left(R_{i}^{1}-R_{i}^{0}\right)}{h_{i}}=\frac{\left[R_{i}^{*}\left(z_{i},\left(1+h_{i}\right) w_{i}, t_{i}\right)-R_{i}^{*}\left(z_{i}, w_{i}, t_{i}\right)\right]}{h_{i}} \leq 0
$$

Esta é a versão não paramétrica dos resultados de Panzar \& Rosse (1987). Assim, (11) indica que o aumento do custo sempre resultará em uma redução proporcional na receita da firma $i$. Logo, ao supor que a forma reduzida apresentada é diferenciável, tomar o limite de (11) com $h_{i} \rightarrow 0$ e dividir o resultado por $R_{i}^{*}$ produz a seguinte prova:

$$
H_{i}^{*} \equiv \sum w_{i}\left(\frac{\partial R_{i}^{*}}{\partial w_{i}}\right) / R^{*} \leq 0
$$

A Estatística H, proposta por Panzar \& Rosse (1987) e apresentada em (12), estabelece que a soma das elasticidades-preço dos fatores da forma reduzida de uma firma monopolista deve ser negativa. Essa soma representa a mudança na receita quando todos os fatores da firma $i$ se elevarem em $1 \%$. Com isso, é possível responder o que acontecerá com a receita de uma firma quando seus custos marginais subirem em $1 \%$. Para uma firma monopolista, espera-se que o incremento no preço dos insumos reduza a receita total, dado que esta empresa estará atuando na parte elástica da curva da demanda. Assim, satisfaz as condições de equilíbrio de longo prazo e as questões de exogeneidade.

Uma Estatística $\mathrm{H}$ negativa indicará um mercado monopolizado. Se a Estatística $\mathrm{H}$ estiver entre 0 e 1 , o mercado será uma concorrência monopolística. Se a Estatística $\mathrm{H}$ for exatamente igual a 1, o mercado será classificado como um puro mercado concorrencial.

No entanto, mesmo firmas competitivas podem exibir uma Estatística $\mathrm{H}$ negativa, se o mercado estiver em uma estrutura de desequilíbrio. Desta forma, testes de equilíbrio de longo prazo devem ser realizados para se garantir a robustez do resultado apresentado pela Estatística $\mathrm{H}$.

Este teste pode ser implementado ao utilizar as mesmas variáveis exógenas utilizadas para a análise da estatística de $P \& Z$, porém sobre algum índice de lucratividade. Comumente, usa-se o lucro liquido sobre o capital próprio para 
avaliar o equilíbrio. Se, neste caso, $\mathrm{H}$ for igual a zero $(\mathrm{H}=0)$, as taxas ajustadas pelos riscos dos retornos entre os bancos vão se equalizar, indicando que as observações em questão representam um equilíbrio de longo prazo Molyneux et al. (1994). Esta relação fica perceptível na equação (3), onde o lucro é a receita total menos o custo total. Logo, se o custo foi subtraído, este não poderá ter impacto sobre a variável dependente, tal como se prevê que ocorra com a Estatística H. Logo, se o lucro estimado sobre os três custos de referência de $P \& Z$ for estatisticamente significativo, há a indicação de que, por meio dos dados, todos os custos não foram subtraídos da função de lucro e consequentemente, estes dados não estão em equilíbrio de longo prazo.

\section{Metodologia}

\subsection{Modelo analítico e os procedimentos}

A equação da forma reduzida que estima a Estatística H é amplamente tratada na literatura. A Estatística $\mathrm{H}$ foi calculada de duas formas. Inicialmente, foi estimado um Painel mensal no período de 2009 a 2016 que analisa as instituições financeiras conforme suas características (Banco do Brasil, Caixa Econômica Federal, bancos privados e todos os bancos). Posteriormente, foi estimada a Estatística $\mathrm{H}$ local, que passa a indicar a distribuição da estatística de cada banco em torno de uma média suavizada. As equações nas formas reduzidas para ambos os casos são apresentadas abaixo:

$$
\begin{gathered}
\ln \left(R T_{i t}\right)=\alpha_{i / t}+\beta \ln \left(\omega_{1, i t}\right)+\gamma \ln \left(\omega_{2, i t}\right)+\delta \ln \left(\omega_{3, i t}\right)+\theta \ln \left(Z_{i t}\right)+\varepsilon_{i t} \\
\ln \left(R O A_{i t}\right)=\alpha_{(i / t)}+\beta \ln \left(\omega_{(1, i t)}\right)+\gamma \ln \left(\omega_{(2, i t)}\right)+\delta \ln \left(\omega_{(3, i t)}\right)+ \\
\theta \ln \left(Z_{i t}\right)+\varepsilon_{i t}
\end{gathered}
$$

onde RT é a Receita Total e ROA é a divisão entre o Lucro Líquido e o Capital Próprio (que será usado para o teste de equilíbrio de longo prazo), $\omega_{1, i m t}$ representa o custo de captação, $\omega_{2, i m t}$ representa o impacto dos custos administrativos sobre o ativo fixo e $\omega_{3, \text { imt }}$ evidencia os custos com pessoais dividido pelos ativos totais. As angulações $\alpha, \beta, \gamma, \delta$ e $\theta$ são os coeficientes das variáveis exógenas. $Z$ representa quatro variáveis de controle, onde duas delas foram construídas da seguinte forma: divisão entre capital próprio e ativos totais (Q_ASSETS) e total de empréstimos divididos por ativos totais (L_ASSETS). As últimas variáveis de controle são uma variável de tendência e a provisão para créditos duvidosos. Os subscritos " $i$ " e " $t$ " representam os bancos, por CNPJ, e o período, por mês, respectivamente. O coeficiente $\alpha_{(i / t)}$ são os parâmetros fixos a serem estimados para $i$ no caso da Estatística $\mathrm{H}$ tradicional ou para $t$ no caso da Estatística H local.

Também foi estimada uma regressão local para cada banco para cada mês da amostra. O procedimento para esta estimação considerou um painel onde os meses são os clusters e os CNPJ's (Cadastro Nacional da Pessoa Jurídica) são avaliados dentro cada cluster. Essa relação é justificável dada a existência do mercado interfinanceiro onde os CNPJs interagem entre si, realizando empréstimos interbancários para saldar suas posições de reservas sem precisar 
recorrer ao Bacen (Figura 3). As posições das instituições financeiras também podem se alterar, dada a característica de rolagem de empréstimo mediante a obtenção de saldos em diferentes bancos. Assim, ao considerar essas características do sistema financeiro, estimou-se um painel com efeitos fixos para o tempo utilizando a equação (15).

Figura 3: Correlação entre as instituições financeiras no mercado de empréstimos do Brasil.

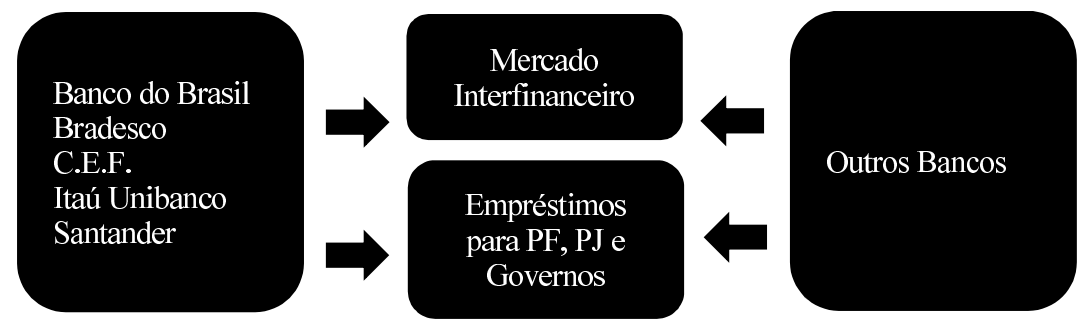

Fonte: Desenvolvido pelos autores.

A partir desta estimativa, foram obtidos os resíduos $\mu_{i t}$. Estes representam tudo de $\ln \left(R T_{i t}\right)$ que não foi explicado pelos controles $Z_{i t}$. Posteriormente, foram estimadas as equações (16), (17) e (18) e obtidos os resíduos $\mu_{(\omega 1, i t)}, \mu_{(\omega 2, i t)}, \mu_{(\omega 3, i t)}$. Os resíduos dos custos representam tudo sobre os fatores que também não são explicados pelos controles $Z_{i t}$. Por fim, estimou-se a equação 19.

$$
\begin{gathered}
\ln \left(R T_{i t}\right)=\alpha_{i / t}+\theta \ln Z_{i t}+\mu_{i t} \\
\ln \left(\omega_{1, i t}\right)=\alpha_{i / t}+\theta \ln Z_{i t}+\mu_{\omega 1, i t} \\
\ln \left(\omega_{3, i t}\right)=\alpha_{i / t}+\theta \ln Z_{i t}+\mu_{\omega 2, i t} \\
\ln \left(\omega_{3, i t}\right)=\alpha_{i / t}+\theta \ln Z_{i t}+\mu_{\omega 3, i t} \\
\mu_{i t}=\alpha_{i / t}+\mu_{\omega 1, i t}+\mu_{\omega 2, i t}+\mu_{\omega 3, i t}+\varepsilon_{\mu, i t}
\end{gathered}
$$

$\mathrm{O}$ valor da Estatística $\mathrm{H}$ para cada instituição financeira em cada mês foi obtido através do valor previsto da equação (19), pois esta previsão indica tudo sobre os custos que não é explicado pelos controles que, por sua vez, explicam tudo sobre a receita que também não é explicado pelos controles. A partir desta estimativa da Estatística $\mathrm{H}$, efetuou-se então uma regressão local descrita genericamente por $y_{i t}=\mu\left(x_{i t}\right)+\varepsilon_{(y, i t)}$, onde $x_{i}$ representa os meses avaliados (janeiro de 2009 a dezembro de 2016) do CNPJ $i$ e, $y_{i t}$ é a Estatística $\mathrm{H}$ para cada CNPJ em cada período de tempo. O termo $\varepsilon_{y, i t}$, representa o erro, que assume ser independente e identicamente distribuído (i.i.d.) com média zero e variância constante.

A função $\mu\left(x_{i t}\right)$ é desconhecida, mas é localmente bem definida (encontrada por meio da aproximação de Taylor). Assim, $\mu\left(x_{i t}\right)$ é localmente aproximada por uma simples classe de funções paramétricas. Normalmente, a literatura utiliza ou uma função linear ou funções polinomiais quadráticas para 
aproximar a função $\mu\left(x_{i t}\right)$ localmente. Funções com postos mais elevados tendem a ser mais difíceis de serem computadas. O ajuste a ser apresentado neste texto segue Tabak et al. (2015), que utilizaram um ajuste linear polinomial.

O próximo passo foi definir a largura da banda $h(b)$ e suavizar uma janela $(x-h(b), x+h(b))$. Assim, o ajuste ocorre ao definir um ponto de $b$, no qual a vizinhança é baseada na estrutura espacial dos dado, limitada pela variável independente. Este ponto, $b$ segue o valor de 0,6 pois assim é definido na literatura padrão (Loader 1999, Simonoff 1996, Tabak et al. 2015).

Com a janela definida, o último passo foi definir uma função de peso que é conhecida como núcleo, que em inglês é chamada de kernel. O núcleo mais comum utilizado e que será assumido nesta pesquisa é uma função tripla, recomendada por Simonoff (1996).

Por fim, cabe reportar que todas as estimativas realizadas são robustas com correção da matriz de variância e covariância em cada cluster. Os desvios padrão da Estatística $\mathrm{H}$ foram calculados mediante o método Delta.

\subsection{Variáveis e fonte dos dados}

A análise da Estatística $\mathrm{H}$ levou em consideração o documento 4010 do Banco Central do Brasil, que traz os balancetes de todos os bancos brasileiros. Apesar das críticas de Cardoso et al. (2016), a análise por meio do documento 4010 foi realizada somente para as instituições que apresentaram informações ao longo de todo o período ${ }^{9}$. Assim, se uma instituição deixou de apresentar informações financeiras em janeiro de 2012 (por exemplo), então esta instituição foi excluída da amostra. Ao adotar tal critério, elimina-se o efeito de dupla contagem dado pela questão dos conglomerados que participaram de alguma Fusão e Aquisição (F\&A) no período. Há outro fator que pesou a favor do relatório 4010 e contra o relatório 4040. É que neste, durante todos os meses dos anos de 2009 e 2010, o Banco do Brasil (BB) e a Caixa Econômica Federal (CEF) não foram considerados como conglomerados. A introdução destes bancos ocorreu somente a partir de 2011, inviabilizando a utilização do documento 4040 no período proposto. As contas utilizadas do relatório 4010 são apresentadas na seguinte tabela:

Tabela 4: Contas do documento 4010 utilizadas na análise da Estatística $\mathrm{H}$

\begin{tabular}{llll}
\hline Conta & Nome da Conta & Conta & Nome da Conta \\
\hline 16000001 Operações de Crédito & 41500002 & Depósitos a Prazo \\
16900008 & Provisões p/ créditos duvid. & 70000009 & C. de Resultado Credora \\
20000004 & Permanente & 80000006 & C. de resultado devedoras \\
21000003 & Investimentos & 81100008 & Despesas de captação \\
39999993 & Total Geral do Ativo & 81200001 Obrigações por empréstimos \\
41000007 Depósitos & 81700006 Despesas administrativas \\
\hline
\end{tabular}

Fonte: relatório 4010 (Bacen)

Das variáveis que compõem as equações (13) e (14), a despesa com pessoal foi utilizada para construir $\omega_{3, i m t}$. A variável LL foi construída a partir

\footnotetext{
${ }^{9}$ Como medida de robustez, as Estatísticas H propostas foram calculadas para todos os bancos de varejo Comerciais e múltiplos, Banco do Brasil e Caixa Econômica Federal contidos no relatório 4010 .
} 
das contas acima apresentadas. A variável despesa com pessoal é resultado da subtração entre as despesas operacionais e as despesas administrativas. As despesas operacionais resultam das somas entre despesas com vendas e despesas administrativas. O lucro líquido foi gerado a partir da subtração das contas de resultado credora e devedora, respectivamente.

$\mathrm{Na}$ Tabela 5 encontra-se o resumo descritivo das principais variáveis utilizadas para estimar a Estatística $\mathrm{H}$. Todas as variáveis estão em escala logarítmica, foram deflacionadas (base janeiro de 2009) e dessazonalizadas pelo método de variáveis binárias.

Tabela 5: Estatísticas descritivas das principais variáveis utilizadas na Estatística H (2009-2016)

\begin{tabular}{lcrrrc}
\hline Variáveis Dependentes & Obs. & Média & D.P. & Min. & Max. \\
\hline Receita Total & 4224 & 20,82 & 2,33 & 14,10 & 29,34 \\
ROA & 3606 & 17,40 & 2,32 & 6,46 & 26,74 \\
\hline Custos de captação / tipo de banco & Obs. & Média & D.P. & Min. & Max. \\
\hline W1 - Banco do Brasil & 96 & $-0,00$ & 0,07 & $-0,76$ & 0,70 \\
W1 - Caixa Econômica Federal & 96 & 0,00 & 0,04 & $-0,24$ & 0,52 \\
W1 - Bancos Múltiplos e Comerciais & 4032 & $-0,00$ & 1,19 & $-2,37$ & 6,57 \\
W1 - Todos os Bancos & 4224 & $-0,00$ & 1,24 & $-2,37$ & 6,57 \\
\hline W2 - Banco do Brasil & 96 & $-0,00$ & 0,04 & $-0,43$ & 0,24 \\
W2 - Caixa Econômica Federal & 96 & 0,02 & 0,16 & 0,00 & 1,48 \\
W2 - Bancos Múltiplos e Comerciais & 4032 & 0,06 & 1,37 & $-3,83$ & 4,77 \\
W2 - Todos os Bancos & 4224 & 0,02 & 0,78 & $-2,68$ & 3,45 \\
\hline W3 - Banco do Brasil & 96 & $-0,01$ & 0,10 & $-1,30$ & 0,00 \\
W3 - Caixa Econômica Federal & 96 & $-0,01$ & 0,10 & $-1,08$ & 0,00 \\
W3 - Bancos Múltiplos e Comerciais & 4032 & 0,05 & 0,07 & $-2,68$ & 3,45 \\
W3 - Todos os Bancos & 4224 & 0,08 & 1,44 & $-3,83$ & 4,77 \\
\hline Controles & Obs. & Média & D.P. & Min. & Max. \\
\hline Q ASSETS & 4224 & $-6,37$ & 2,84 & $-18,06$ & $-2,37$ \\
L ASSETS & 4224 & $-2,70$ & 1,07 & $-7,28$ & $-1,11$ \\
Provisões & 4224 & 18,85 & 2,67 & 7,63 & 28,11 \\
\hline * Fonte: relatorio 4010 Bacen) & & & & &
\end{tabular}

${ }^{*}$ Fonte: relatório 4010 (Bacen)

Para o cálculo da Estatística H levou-se em consideração 4.224 observações. Este é o total de observações dada pela Receita Total. Para se chegar a este valor foram 96 observações ${ }^{10}$ diferentes de zero para o Banco do Brasil e 96 observações para a Caixa Econômica Federal. Para os bancos privados foram 4.032 observações diferentes de zero. Os zeros foram substituídos no lugar dos valores perdidos (missings) para que a estimativa coubesse em apenas uma regressão. O teste de equilíbrio levou em consideração menos observações devido à quantidade de dados observados da variável ROA.

\section{Resultados e Discussão}

A primeira análise da Estatística $\mathrm{H}$ a ser apresentada contempla toda a indústria bancária (considerando os 44 bancos que participaram initerruptamente) ao longo dos 96 meses analisados. A Tabela 6 contempla a Estatística H por

\footnotetext{
${ }^{10}$ Somadas as observações do Banco do Brasil, Caixa Econômica Federal e das demais instituições, chega-se às 4.224 observações aferidas em uma única regressão.
} 
tipo de banco, considerando somente o Banco do Brasil, a Caixa Econômica Federal e os bancos privados (múltiplos ou comerciais).

Tabela 6: Estatística H por tipo de banco e geral para o período mensal de 2009 a 2016

\begin{tabular}{l|c|c|r|r}
\hline Tipos de Bancos & Estatística H & Desvio Padrão & Z-Valor & $\mathbf{P}>|\mathbf{z}|$ \\
\hline Banco do Brasil & $-0,947^{* * * *}$ & $(0,055)$ & $-17,34$ & 0,000 \\
Caixa Econômica Federal & $-2,016^{* * *}$ & $(0,191)$ & $-10,54$ & 0,000 \\
Bancos Privados & $0,486^{* * *}$ & $(0,118)$ & 4,13 & 0,000 \\
Todos os Bancos & $0,461^{* * *}$ & $(0,117)$ & 3,94 & 0,000 \\
\hline Fonte: Resultado da Pesquisa. \\
Desvio padrão nos parênteses \\
${ }^{*} \mathrm{p}<0,1 ;{ }^{* *} \mathrm{p}<0,05 ;{ }^{* * * *} \mathrm{p}<0,01$
\end{tabular}

Os resultados indicam que, quando analisado ao longo de todo o período, na média, o Banco do Brasil detém e exerce seu poder de monopólio. A mesma situação ocorre com a Caixa Econômica Federal que, por força de lei, detém o monopólio de vários serviços prestados pelo governo federal. Quando analisados apenas os bancos privados, a conduta parece ser, tal como aponta a literatura nacional e internacional, uma concorrência monopolística. E, com menor significância estatística, ao considerar todos os 44 bancos da amostra em conjunto, a relação de concorrência monopolística se mantém.

No entanto, há uma ressalva com relação aos bancos públicos. Ambos não apresentaram equilíbrio de longo prazo na análise de todo o período (Tabela 11). Entre os anos de 2012 e 2013, estes bancos foram utilizados como canal direto de redução das taxas de juros. Assim, neste período, tanto as taxas de alavancagem quanto a rentabilidade dos bancos públicos não condiziam com aquela apresentada pelas demais instituições financeiras. O equilíbrio de longo prazo para os bancos públicos somente foi verificado após o ano de $2014^{11}$ (quando as políticas de intervenção direta no mercado bancário cessaram - Tabela 12). Note que todos os bancos apresentaram na média equilíbrio de longo prazo. Para que isso ocorresse, os bancos privados deveriam deslocar seus recursos para outros segmentos que não o de empréstimos, caso contrário, os bancos públicos apresentariam uma estratégia concorrencial. Isso corrobora o argumento de que os bancos privados passaram a financiar o governo mediante as ações anticíclicas das instituições públicas.

Para verificar se há uma diferença na conduta das instituições após o ano de 2014, estimou-se a conduta de todos os bancos da amostra para este período (Tabela 7). A partir dos resultados, conclui-se que a estrutura em si não mudou, mas o mercado tornou-se mais competitivo para os bancos privados, enquanto que as instituições públicas ampliaram o exercício do poder de monopólio - quando considerado todo o universo, a medida de concorrência se mantêm. Porém, em um patamar mais baixo, dado o peso dos bancos públicos.

Observa-se que, antes da edição da portabilidade do crédito bancário, os bancos públicos pareciam não competir com seus pares privados - atuando de forma anticíclica e provendo o mercado com crédito quando os pares privados não o faziam. Entretanto, após a edição dessa portabilidade, tal relação

\footnotetext{
${ }^{11} \mathrm{Na}$ análise com $114 \mathrm{CNPJs}$, a CEF continuou fora do equilíbrio de longo prazo. Note que, neste caso, alguns bancos deveriam sair do sistema para que a alavancagem da CEF fosse sustentável. É o que acontece quando os bancos que estão prestes a sair da amostra saem.
} 
Tabela 7: Estatística H por tipo de banco e geral para o período mensal de 2014 a 2016

\begin{tabular}{l|c|r|r|r}
\hline Tipos de Bancos & Estatística H & Desvio Padrão & Z-Valor & $|\mathbf{P}>| \mathbf{z} \mid$ \\
\hline Banco do Brasil & $-2,1479^{* * *}$ & $(0,2394)$ & $-8,97$ & 0,000 \\
Caixa Econômica Federal & $-7,1864^{* * *}$ & $(0,4446)$ & $-16,16$ & 0,000 \\
Bancos Privados & $0,7188^{* * *}$ & $(0,1303)$ & 5,52 & 0,000 \\
Todos os Bancos & $0,6966^{* * *}$ & $(0,1288)$ & 5,41 & 0,000 \\
\hline Fonte: Resultado da Pesquisa. & & & \\
Desvio padrão nos parênteses &
\end{tabular}

parece ter se encaminhado a um equilíbrio. Os bancos públicos passaram a exercer ainda mais o seu poder de monopólio. Provavelmente, segmentos internos (mercado de depósitos, depósitos a prazo, sistema de pagamentos, etc.) que poderiam não ser monopolizados passaram a sê-lo. Em contrapartida, os bancos privados parecem ter acirrado a concorrência. Assim, em média, os valores indicam um mercado mais próximo ao equilíbrio, que é representando pelo valor zero. Mas, ainda assim, é considerado como uma concorrência monopolística, pois o valor da Estatística $\mathrm{H}$ de todos os bancos também é estatisticamente diferente da unidade ${ }^{12}$.

O teste de equilíbrio de longo prazo para o período de 2014 em diante identificou que os custos $\mu_{1}, \mu_{2}$ e $\mu_{3}$ são estatisticamente iguais a zero (Tabela 12) e, portanto, os resultados encontrados para todos os bancos, inclusive para os bancos públicos, são considerados válidos. Isso indica que o aumento no preço de um banco com variação positiva da lucratividade necessariamente irá induzir a redução do preço de outro banco, ou até mesmo a saída de outro banco do mercado.

A distribuição da Estatística $\mathrm{H}$ das instituições financeiras em torno da Estatística $\mathrm{H}$ localmente estimada (Figura 4), permite a avaliar e relacionar as variações das alíquotas de compulsório com a evolução da estratégia média das instituições financeiras. Note que entre 2009 e 2010 a maior variação foi sobre os depósitos a prazo (6,5 pontos percentuais - decompostos em 1,5 pontos percentuais em fevereiro de 2010 e o restante em dezembro de 2010) enquanto que a variação da alíquota para a poupança rural e para o depósito à vista foram de um ponto percentual cada (a variação ocorreu em junho de 2010). Neste período percebe-se que o segmento bancário passou, na média, de concorrencial para uma relação de oligopólio e voltou ao equilíbrio somente em julho de 2010, um mês após a alteração da alíquota de compulsório dos recursos à vista e da poupança rural (Tabela 13).

Em junho de 2011, uma nova alteração da alíquota do compulsório sobre os recursos da poupança rural ocorreu e, aproximadamente em agosto de 2011, a Estatística H Local média novamente evoluiu para o ponto de equilíbrio (valor igual a zero), onde permaneceu até meados de julho de 2012. Deste período em diante, no entanto, além do aumento da alíquota de compulsórios em um ponto percentual sobre os recursos à vista, houve um adicional de seis pontos percentuais que permaneceu até setembro de 2012. Como já mencionado, o aumento da alíquota do compulsório sobre os recursos à vista eleva também o nível de alavancagem das instituições financeiras, que acabou por se converter em uma estratégia média de monopólio.

${ }^{12}$ A $5 \%$ de significância. 
Figura 4: Distribuição da Estatística $\mathrm{H}$ em torno da sua média local

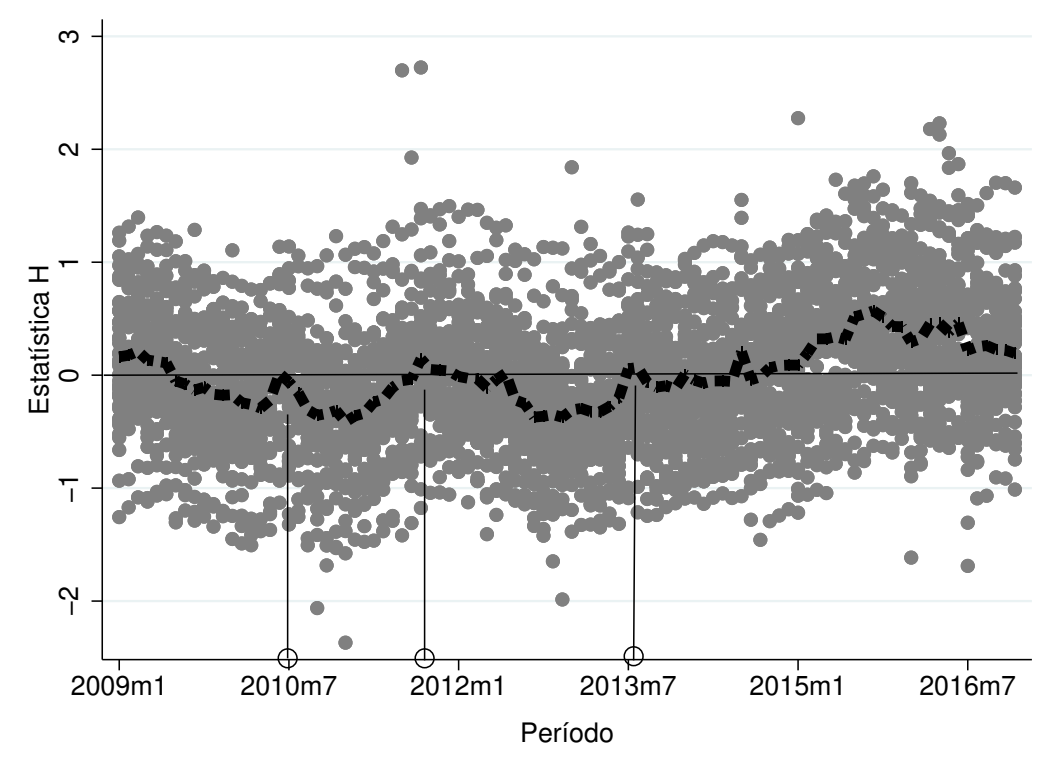

Fonte: Resultado da pesquisa.

No entanto, percebe-se que as variações prudenciais sobre a poupança não promovem um aumento da alavancagem das instituições financeiras e, portanto, não recaem sobre o consumidor final. Isso ocorre, pois praticamente todo o segmento de poupança é regulamentado com baixíssimas margens para os banqueiros. Assim, os recursos que são livres para a movimentação, após satisfeitas todas as reservas técnicas, são os depósitos à vista, cuja sensibilidade parece ser maior, e os depósitos a prazo, que após a variação proposta em 2010 teve sua alíquota elevada apenas em 2015 (quando novamente a Estatística $\mathrm{H}$ voltou a apresentar tendência de queda).

Em janeiro de 2015, as exigibilidades dadas pelo Basileia III passaram a ser oficialmente uma política prudencial. A prática desta parece ter alterado o comportamento das instituições financeiras que se mantiveram até o fim de 2016 em situação de concorrência monopolística.

A análise de cointegração entre as reservas técnicas (Provisão para Créditos Duvidosos) das cinco maiores instituições financeiras com a Estatística $\mathrm{H}$ Local média estimada indica que ambas as séries "caminham" juntas ao longo do tempo. Assim, quando os bancos estão concorrendo entre si, estes aumentam suas provisões para possíveis perdas e quando os mesmos carregam uma estratégia de monopólio, suas provisões são mais baixas. Note que essas reservas são reflexos das variações nos coeficientes do compulsório. Os clusters de variação do retorno das reservas técnicas, até janeiro de 2015, quando os buffers oficialmente se tornaram instrumentos prudenciais, foram exatamente nos períodos de variação dos compulsórios (Figuras 6 no Apêndice).

Das cinco maiores instituições financeiras ${ }^{13}$, a Estatística $\mathrm{H}$ média temporal já havia indicado que os dois bancos públicos exerciam poder de mercado. Através da Estatística H Local (Tabela 8), percebe-se que, das instituições pri-

\footnotetext{
${ }^{13}$ A Figura 10, no Apêndice, evidencia que as cinco instituições financeiras estão sob um mesmo mercado relevante. Os demais bancos atuam localmente.
} 
vadas (entre as cinco maiores), apenas o Bradesco apresentou média diferente da mediana em nível de 5\% de significância. Como a média é maior que a mediana, essa relação é uma evidência de que, na maior parte do tempo, a conduta do Bradesco foi inferior à 0,036 (que é estatisticamente igual a zero) e, portanto, com uma medida de tendência central, nesta parte do tempo, em torno de um valor negativo $(-0,059)$. Assim, é possível inferir que o Bradesco pode ter passado boa parte do tempo exercendo seu poder de mercado.

A mesma situação ocorre com o Santander, pois apesar da média ser igual a mediana, ambas são menores do que zero. Essa relação mostra que, pelo menos na metade do tempo, esta instituição exerceu poder de mercado e que em outra metade ou estava em equilíbrio ou em uma concorrência monopolística.

Tabela 8: Estatística $\mathrm{H}$ das cinco maiores instituições financeiras entre 2009 e 2016

\begin{tabular}{l|c|c|c|c|c}
\hline Tipos de Bancos & H-Média & H-Mediana & Variância & Mínima & Máxima \\
\hline Banco do Brasil & $-0,240^{* * *}$ & $-0,263$ & 0,076 & $-0,748$ & 0,313 \\
Caixa Econômica Federal & $-0,066^{* * *}$ & $-0,072$ & 0,048 & $-0,498$ & 0,447 \\
Bradesco & 0,036 & $-0,059^{* *}$ & 0,149 & $-0,488$ & 1,107 \\
Itaú-Unibanco & $0,105^{* * *}$ & 0,065 & 0,067 & $-0,366$ & 0,798 \\
Santander & $-0,159^{* *}$ & $-0,261$ & 0,526 & $-1,354$ & 1,209 \\
\hline Fonte: Resultado da Pesquisa. \\
Os asteriscos no valor da estatística média indicam que o valor médio é \\
estatisticamente diferente de zero. Os asteriscos no valor da mediana indicam que a \\
diferença média entre a Estatística H média e a Estatística H mediana é diferente de \\
zero (essa relação mostra assimetria ao longo do tempo na conduta de determinado \\
banco). Os testes levaram em consideração somente a Estatística H da instituição em \\
questão ao longo de todo o período. \\
* $<<0,1 ;{ }^{* *}$ p<0,05; *** p<0,01
\end{tabular}

Das cinco maiores instituições financeiras, o Itaú Unibanco foi o único a apresentar Estatística H média e mediana em valores de concorrência monopolística. Porém, em alguns momentos também apresentou mínimas inferiores a zero. Essa relação deve-se ao fato de a instituição manter abertas as agências tanto do Itaú quanto do Unibanco, sem promover demissões no curto prazo. A estratégia corporativa empírica após a fusão foi manter o número de funcionários e reduzir o custo com pessoal ao longo do tempo, mediante aposentadorias. A redução do número de agências bancárias passou a ocorrer somente a partir do primeiro trimestre de 2017 (Itaú 2017).

Considerando todas as instituições financeiras (Tabela 14), o Banco Bradesco também apresentou comportamento semelhante ao do Itaú Unibanco, enquanto o Banco Santander apresentou, na maior parte do tempo, uma conduta de monopólio. Note que a diferença entre as duas estimativas para o Banco Santander é exatamente no período em que o banco permaneceu como monopólio. Por questão de prudência, esta pesquisa optou pelo menor tempo e pela maior significância estatística, que foi para o caso com 44 CNPJs.

\section{Conclusões}

O objetivo deste trabalho foi relacionar a conduta das instituições financeiras frente às políticas macroprudenciais e a política de portabilidade bancária editadas no período de 2009 a 2016. Para isso, estimou-se a Estatística H por meio de um painel, analisando todas as instituições financeiras ao longo dos 
96 meses e concluiu-se que estas instituições financeiras compõem, na média, uma concorrência monopolística. No entanto a análise individual dos bancos públicos indicou que estes exercem seu poder de mercado. Assim, estimouse a Estatística $\mathrm{H}$ das instituições financeiras localmente, considerando todas as instituições financeiras dentro do mesmo cluster, que passou a ser cada unidade de tempo (o mês).

A partir desta estimativa, aplicou-se uma regressão local e pode-se assim identificar a distribuição da conduta das instituições financeiras em torno da média suavizada ao longo do período. Percebeu-se, então, que a Estatística $\mathrm{H}$ média das instituições financeiras passou a maior parte do tempo entre $2009 \mathrm{e}$ 2013 com valores negativos, indicando uma conduta de monopólio no período. Após a implementação da política de portabilidade, em 2014, percebe-se que as instituições financeiras entraram na zona de equilíbrio, por onde permaneceram até janeiro de 2015. A partir deste mês, a política prudencial de buffers do Basileia III passou a ser uma política de crédito oficial e, apesar de não ter sido acionado no período, essa relação transformou a conduta dos bancos em uma concorrência monopolística.

A Estatística $\mathrm{H}$ de $\mathrm{P} \& \mathrm{Z}$, por ser de forma reduzida, somente analisa a atuação das instituições financeiras como um todo. Assim, a continuação deste trabalho pode ocorrer por meio de modelos estruturais que utilizam dados desagregados das instituições financeiras em seus ramos de atuação (empréstimos, câmbio, depósitos a vista, depósitos a prazo, sistemas de pagamentos, entre outros) para analisar a conduta das instituições financeiras em cada um destes segmentos separadamente. Outra oportunidade de trabalho é analisar os custos de mudanças que as instituições bancárias impõem sobre seus clientes ao longo do período analisado por este artigo. Com a análise de cada segmento e com os custos de mudanças é possível desenvolver análises mais detalhadas e direcionadas que possam fomentar a discussão de políticas públicas de redução do spread bancário brasileiro, que ainda é um dos mais elevados do mundo.

\section{Agradecimentos}

Somos gratos à Fundação de Amparo à Pesquisa do Estado de Minas Gerais (FAPEMIG) e à Coordenação de Aperfeiçoamento de Pessoal de Nível Superior (CAPES) pelo apoio financeiro durante o desenvolvimento desta pesquisa. Afirmamos também que as idéias, os resultados e as conclusões discutidas neste artigo são independentes das fundações e de inteira responsabilidade dos autores.

\section{Referências Bibliográficas}

Allen, F., Krzysztof, J. \& Kowalewski, O. (2013), 'The Effects of Foreign and Government Ownership on Bank Lending Behavior During a Crisis in Central and Eastern Europe'.

ANBIMA (2010), 'Basileia III: Novos desafios para a adequação da regulação bancária'. Perspectivas.

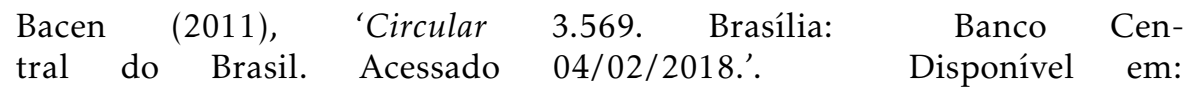


<http://www.bcb.gov.br/pre/normativos/busca/downloadNormativo.asp?ar quivo/Lists/Normativos/Attachments/49277/Circ_3569_v15_L.pdf >.

Bacen (2013), 'Recomendações de Basiléia'. Disponível em: $<$ https://www.bcb.gov.br/acessoinformacao/legado?url=https:\%2F\%2Fwww. bcb.gov.br\%2Ffis\%2Fsupervisao\%2Fbasileia.asp $>$.

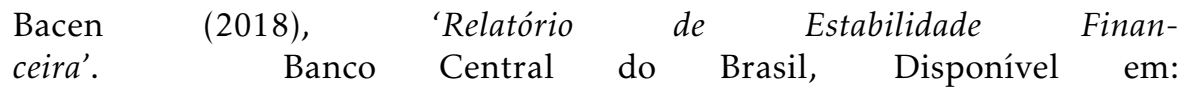
<https://www.bcb.gov.br/htms/estabilidade/2018_10/refPub.pdf>.

Brei, M. \& Schclarek, A. (2015), 'A theoretical model of bank lending: Does ownership matter in times of crisis?', Journal of Banking and Finance 50, 298307.

Camargo, P. O. (2009), A evolução recente do setor bancário no Brasil [online], São Paulo: UNESP - Cultura Acadêmica, São Paulo.

Cardoso, M., Azevedo, P. F. \& Barbosa, K. (2016), 'Concorrência no setor bancário brasileiro: Bancos individuais versus conglomerados bancários', Pesquisa e Planejamento Econômico 46(1), 113-146.

Delis, M. D. (2010), 'Competitive conditions in the Central and Eastern European banking systems'.

DIEESE (2017), 'Desempenho dos Bancos em 2016'.

Gertler, M. \& Karadi, P. (2011), 'A model of unconvetional monetary policy', Journal of Monetary Economics . 58(1), p. 17-34.

Graupen, A. G. (2015), As Políticas Anticíclicas Brasileiras da Crise Financeira de 2008: Uma análise setorial, São Paulo: Fundação Getúlio Vargas - Escola de Economia de São Paulo.

Itaú (2017), 'Relações com Investidores'. São Paulo: Itaú Unibanco. Acessado 04/02/2018. Disponível em: <http://www.itau.com.br/relacoes-cominvestidores/informacoes-financeiras/apresentacao-de-resultados/1t2017>.

Loader, C. (1999), 'local regression methods', in 'C. Loader, Local Regression and Likelihood. New York: Murray Hill', Murray Hill.

Lucinda, C. R. (2010), 'Competition in the Brazilian Loan Market: an Empirical Analysis', Estudos Econômicos .

Martin, S. (2010), Industrial Organization in Context, New York: Oxford University Press.

Micco, A. \& Panizza, U. (2006), 'Bank ownership and lending behavior', Economics Letters 93, 248-254.

Molyneux, P., Lloyd-Williams, D. \& Thornton, J. (1994), 'Competitive conditions in European banking', Journal of Banking Finance . 18(3): 445-459.

Molyneux, P., Thornton, J. \& Lloyd-Williams, D. (1996), 'Competition and Market Contestability in Japanese Commercial Banking', Journal of Economics and Business . 
Panzar, J. C. \& Rosse, J. N. (1987), 'Testing for monopoly equilibrium', Journal of Industrial Economics . 35(4), 443-456.

Poutineau, J. C. \& Vermandel, G. (2017), 'Global banking and the conduct of macroprudential policy in a monetary union', Journal of Macroeconomics . 54(B), 306-331.

Rocha, F. A. (2001), 'Evolução da Concentração Bancária no Brasil (1994-2000)'. Notas Técnicas do Banco Central do Brasil.

Simonoff, J. S. (1996), Nonparametric Regression. In J. S. Simonoff, (corrected edition), New York: Springer.

Tabak, B. M., Fazio, D. M. \& Cajueiro, D. O. (2012), 'The relationship between banking market competition and risk-taking: do size and capitalization matter?', Journal of Banking E Finance . 36(12): 3366-3381.

Tabak, B. M., Gomes, G. M. \& Junior, M. S. (2015), 'The impact of market power at bank level in risk-taking: the brazilian case', International Review of Financial Analysis . 40, 154-165.

Torres, S. A. (2016), 'Intervenções Governamentais no Mercado de Crédito Bancário Brasileiro: Bancos Públicos e Bancos Privados varejistas competem entre si?’. São Paulo: Fundação Getúlio Vargas. (Dissertação de Mestrado). 


\section{Apêndice}

Tabela 9: Estimativa dos coeficientes da Estatística H (Efeitos fixos para 44 CNPJs)

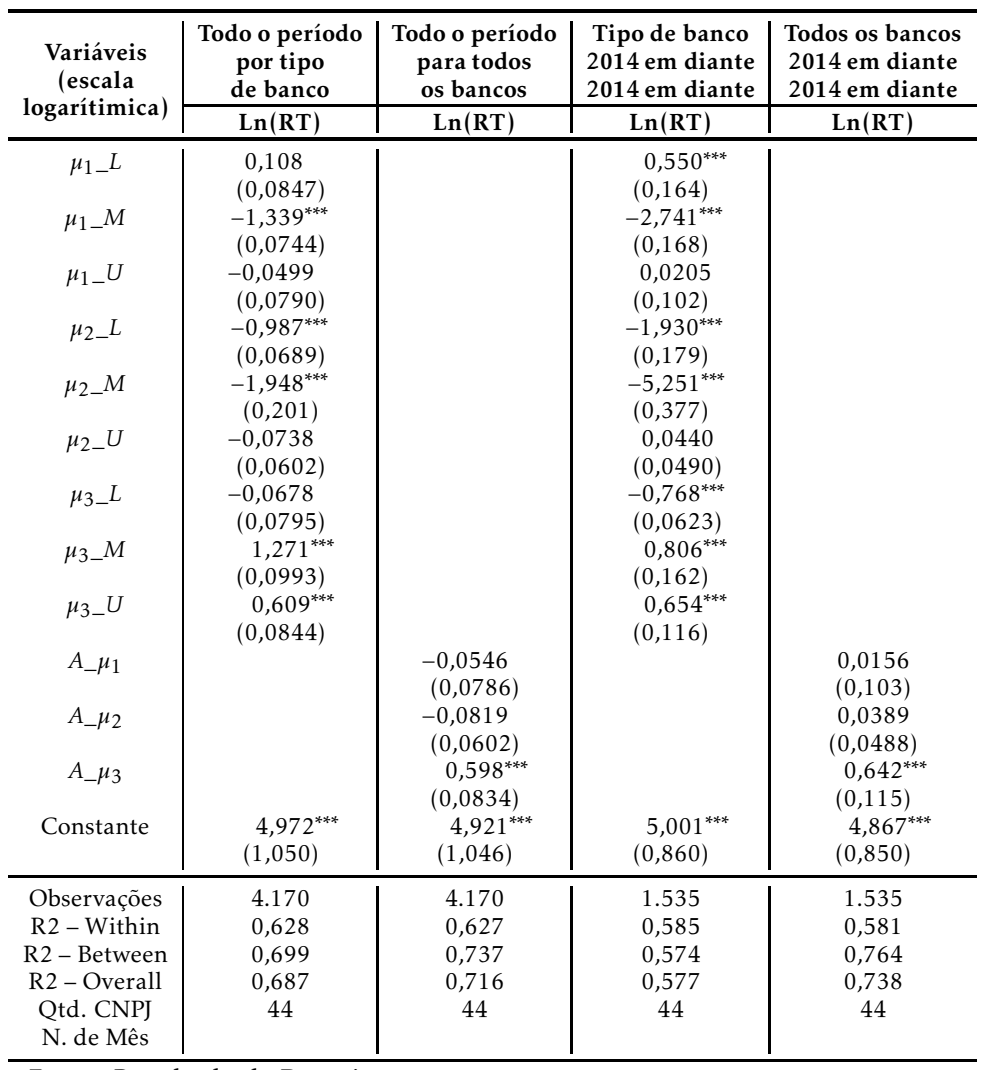

Fonte: Resultado da Pesquisa.

${ }^{* * *} \mathrm{p}<0,01,{ }^{* *} \mathrm{p}<0,05,{ }^{*} \mathrm{p}<0,1$

Erros Padrões Robustos em parênteses. 
Tabela 10: Estimativas para o teste de equilíbrio de longo prazo (Efeitos fixos para 44 CNPJs)

\begin{tabular}{|c|c|c|c|c|}
\hline \multirow{2}{*}{$\begin{array}{c}\text { Variáveis } \\
\text { (escala } \\
\text { logarítimica) }\end{array}$} & $\begin{array}{l}\text { Tipo de Banco - } \\
\text { todo o período }\end{array}$ & $\begin{array}{c}\text { Tipo de Banco } \\
2014 \sim\end{array}$ & $\begin{array}{c}\text { Todos os Bancos - } \\
\text { todo o período }\end{array}$ & $\begin{array}{l}\text { Todos os bancos } \\
2014 \text { em diante }\end{array}$ \\
\hline & Lucro & Lucro & Lucro & Lucro \\
\hline$\mu_{1 \_} L$ & $-0,265^{*}$ & 0,214 & & \\
\hline$\mu_{1} M$ & $\begin{array}{l}(0,133) \\
-1,084^{* * *}\end{array}$ & $\begin{array}{l}(0,178) \\
-3,875^{* * *}\end{array}$ & & \\
\hline & $(0,148)$ & $(0,219)$ & & \\
\hline$\mu_{1 \_} U$ & 0,0798 & 0,127 & & \\
\hline & $(0,0946)$ & $(0,112)$ & & \\
\hline$\mu_{2 \_} L$ & $-0,527^{* * *}$ & 0,000277 & & \\
\hline & $(0,0820)$ & $(0,457)$ & & \\
\hline$\mu_{2} \_M$ & $-1,151^{* * *}$ & $2,381^{* * *}$ & & \\
\hline & $(0,423)$ & $(0,400)$ & & \\
\hline$\mu_{2} \_U$ & 0,0684 & 0,122 & & \\
\hline & $(0,0957)$ & $(0,0810)$ & & \\
\hline$\mu_{3 \_} L$ & $-0,186^{*}$ & $-0,401^{* * *}$ & & \\
\hline & $(0,108)$ & $(0,0603)$ & & \\
\hline$\mu_{3 \_} M$ & $-0,839^{* * *}$ & $1,184^{* * * *}$ & & \\
\hline & $(0,150)$ & $(0,241)$ & & \\
\hline$\mu_{3 \_} U$ & $-0,0741$ & $-0,209^{*}$ & & \\
\hline & $(0,101)$ & $(0,122)$ & & \\
\hline$A \_\mu_{1}$ & & & 0,0879 & $0,219^{* * *}$ \\
\hline & & & $(0,0781)$ & $(0,0757)$ \\
\hline$A_{-} \mu_{2}$ & & & 0,0399 & $-0,000722$ \\
\hline & & & $(0,0905)$ & $(0,0704)$ \\
\hline$A_{-} \mu_{3}$ & & & $-0,0790$ & $-0,194^{*}$ \\
\hline & & & $(0,0891)$ & $(0,102)$ \\
\hline Constante & $-9,796^{* * *}$ & $-9,142^{* * *}$ & $-10,44^{* * *}$ & $-10,94^{* * *}$ \\
\hline & $(0,453)$ & $(1,012)$ & $(0,460)$ & $(0,977)$ \\
\hline Observações & 3,255 & 1,168 & 3,255 & 1,168 \\
\hline R2 - Within & 0,228 & 15,71 & 0,226 & 0,155 \\
\hline R2 - Between & 0,673 & 71,57 & 0,674 & 0,719 \\
\hline R2 - Overall & 0,592 & 59,37 & 0,593 & 0,595 \\
\hline $\operatorname{Corr}(\mathrm{u}, \mathrm{xb})$ & 0,3325 & 0,4591 & 0,3133 & 0,474 \\
\hline Qtd de CNPJs. & 44 & 43 & 44 & 43 \\
\hline
\end{tabular}

Fonte: Resultado da Pesquisa.

*** $\mathrm{p}<0,01,{ }^{* *} \mathrm{p}<0,05,{ }^{*} \mathrm{p}<0,1$

Erros Padrões Robustos em parênteses.

Tabela 11: Equilíbrio de longo prazo (Todo o período)

\begin{tabular}{l|c|c|r|r}
\hline Tipos de Bancos & Estatística H & Desvio Padrão & Z-Valor & $\mathbf{P}>\mathbf{z} \mid$ \\
\hline Banco do Brasil & $-0,917^{* * *}$ & $(0,0539)$ & $-16,99$ & 0,000 \\
Caixa Econômica Federal & $-2,706^{* * *}$ & $(0,2694)$ & $-10,05$ & 0,000 \\
Bancos Privados & 0,293 & $(0,1471)$ & $-0,20$ & 0,484 \\
Todos os Bancos & 0,0563 & $(0,1696)$ & 0,33 & 0,740 \\
\hline
\end{tabular}

Fonte: Resultado da Pesquisa.

Desvio padrão nos parênteses

$\mathrm{H} 0$ : Estatística $\mathrm{H}$ igual a zero.

${ }^{*} \mathrm{p}<0,1 ;{ }^{* *} \mathrm{p}<0,05 ;{ }^{* * *} \mathrm{p}<0,01$ 
Tabela 12: Equilíbrio de longo prazo (2014 em diante)

\begin{tabular}{l|c|c|c|c}
\hline Tipos de Bancos & Estatística H & Desvio Padrão & Z-Valor & $\mathbf{P}>|\mathbf{z}|$ \\
\hline Banco do Brasil & $-0,187$ & $(0,588)$ & $-0,32$ & 0,751 \\
Caixa Econômica Federal & $-0,310$ & $(0,399)$ & $-0,78$ & 0,437 \\
Bancos Privados & 0,040 & $(0,197)$ & 0,20 & 0,840 \\
Todos os Bancos & 0,046 & $(0,194)$ & 0,24 & 0,813 \\
\hline
\end{tabular}

Fonte: Resultado da Pesquisa.

Desvio padrão nos parênteses

H0: Estatística H igual a zero.

${ }^{*} \mathrm{p}<0,1 ;{ }^{* *} \mathrm{p}<0,05 ;{ }^{* * *} \mathrm{p}<0,01$

Tabela 13: Evolução do coeficiente da alíquota do compulsório entre 2003 e 2016

\begin{tabular}{|c|c|c|c|c|c|c|c|}
\hline \multirow[t]{2}{*}{ Período } & \multirow{2}{*}{$\begin{array}{c}\text { Recursos } \\
\text { à vista }\end{array}$} & \multirow{2}{*}{$\begin{array}{c}\text { Depósitos } \\
\text { a prazo }\end{array}$} & \multicolumn{2}{|c|}{ Poupança } & \multicolumn{3}{|c|}{ Exigibilidade Adicional } \\
\hline & & & Habitacional & Rural & Rec. à vista & Dep. a prazo & Poupança \\
\hline ago/03 & 0,45 & $"$ & $"$ & $"$ & $"$ & $"$ & $"$ \\
\hline $\mathrm{mai} / 08$ & " & $"$ & " & " & $"$ & $"$ & $"$ \\
\hline jul/08 & $"$ & $"$ & $"$ & $"$ & $"$ & $"$ & $"$ \\
\hline set/08 & $"$ & $"$ & $"$ & " & $"$ & $"$ & $"$ \\
\hline out $/ 08$ & 0,42 & $"$ & $"$ & $"$ & 0,05 & 0,05 & $"$ \\
\hline nov/08 & $"$ & $"$ & $"$ & 0,15 & $"$ & " & $"$ \\
\hline jan/09 & $"$ & $"$ & $"$ & $"$ & $"$ & 0,04 & $"$ \\
\hline set/09 & " & 0,135 & $"$ & $"$ & " & " & $"$ \\
\hline $\mathrm{fev} / 10$ & " & 0,15 & $"$ & " & 0,08 & 0,08 & " \\
\hline jun/10 & 0,43 & $"$ & $"$ & 0,16 & $"$ & $"$ & $"$ \\
\hline $\mathrm{dez} / 10$ & $"$ & 0,2 & $"$ & $"$ & 0,12 & 0,12 & $"$ \\
\hline $\mathrm{abr} / 11$ & " & " & $"$ & " & $"$ & " & $"$ \\
\hline jun/11 & " & $"$ & " & 0,17 & " & $"$ & $"$ \\
\hline jul/11 & $"$ & $"$ & $"$ & $"$ & $"$ & $"$ & $"$ \\
\hline $\mathrm{jul} / 12$ & 0,44 & " & $"$ & $"$ & 0,06 & $"$ & $"$ \\
\hline set/12 & " & $"$ & " & " & 0 & " & $"$ \\
\hline out/12 & " & " & " & " & $"$ & 0,11 & $"$ \\
\hline $\mathrm{dez} / 12$ & $"$ & " & $"$ & $"$ & $"$ & $"$ & $"$ \\
\hline jul/13 & $"$ & " & " & 0,18 & $"$ & $"$ & $"$ \\
\hline jul/14 & 0,45 & " & " & $"$ & " & $"$ & $"$ \\
\hline out/14 & $"$ & " & $"$ & 0,13 & " & $"$ & $"$ \\
\hline jun/15 & $"$ & " & 0,245 & 0,155 & " & $"$ & 0,055 \\
\hline ago/15 & $"$ & 0,25 & & & " & " & " \\
\hline
\end{tabular}

Fonte: Adaptado do Banco Central do Brasil

Tabela 14: Estatística H Local das cinco maiores instituições financeiras entre 2009 e 2016

\begin{tabular}{l|c|c|c|c|c}
\hline Tipos de Bancos & H-Média & H-Mediana & Variância & Mínima & Máxima \\
\hline Banco do Brasil & $-0,334^{* * *}$ & $-0,351$ & 0,071 & $-0,870$ & 0,242 \\
Caixa Econômica Federal & $-0,402^{* * *}$ & $-0,456^{* *}$ & 0,053 & $-0,815$ & 0,152 \\
Bradesco & $0,200^{* * *}$ & $0,077^{* * *}$ & 0,142 & $-0,304$ & 1,391 \\
Itaú-Unibanco & $0,274^{* * *}$ & 0,232 & 0,077 & $-0,162$ & 1,071 \\
Santander & 0,092 & $-0,021^{*}$ & 0,414 & $-0,930$ & 1,392 \\
\hline
\end{tabular}

Fonte: Resultado da Pesquisa.

Os asteriscos no valor da estatística média indicam que o valor médio é estatisticamente diferente de zero. Os asteriscos no valor da mediana indicam que a diferença média entre a Estatística $\mathrm{H}$ média e a Estatística $\mathrm{H}$ mediana é diferente de zero (essa relação mostra assimetria ao longo do tempo na conduta de determinado banco). Os testes levaram em consideração somente a Estatística $\mathrm{H}$ da instituição em questão ao longo de todo o período.

${ }^{*} \mathrm{p}<0,1 ;{ }^{* *} \mathrm{p}<0,05 ;{ }^{* *} \mathrm{p}<0,01$ 
Figura 5: Distribuição da Estatística $\mathrm{H}$ em torno da sua média suavizada por CNPJ.

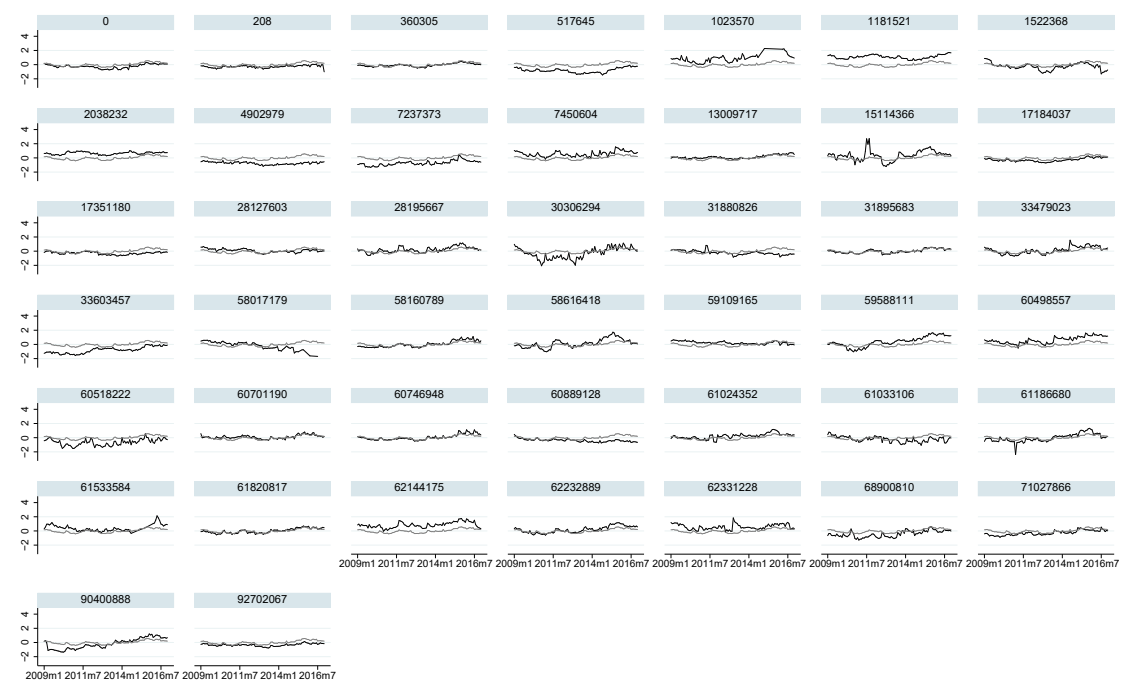

Período Mensal

Estatística H do Banco Média Local Suavizada

Fonte: Resultado da Pesquisa.

Tabela 15: Estatística $\mathrm{H}$ por tipo de banco e geral para o período mensal de 2009 a 2016 (114 CNPJs)

\begin{tabular}{l|c|c|r|r}
\hline Tipos de Bancos & Estatística H & Desvio Padrão & Z-Valor & $|\mathbf{P}>| \mathbf{z} \mid$ \\
\hline Banco do Brasil & $-1,321^{* * *}$ & $(0,041)$ & $-32,10$ & 0,000 \\
Caixa Econômica Federal & $-2,692^{* * *}$ & $(0,237)$ & $-11,34$ & 0,000 \\
Bancos Privados & $0,397^{* * *}$ & $(0,097)$ & 4,07 & 0,000 \\
Todos os Bancos & $0,382^{* * *}$ & $(0,097)$ & 3,92 & 0,000 \\
\hline
\end{tabular}

Fonte: Resultado da Pesquisa.

Desvio padrão nos parênteses

H0: Estatística H igual a zero.

${ }^{*} \mathrm{p}<0,1 ;{ }^{* *} \mathrm{p}<0,05 ;{ }^{* * *} \mathrm{p}<0,01$ 
Figura 6: Análise de Cointegração entre as reservas técnicas das cinco maiores instituições financeiras e a Estatística H Local média.
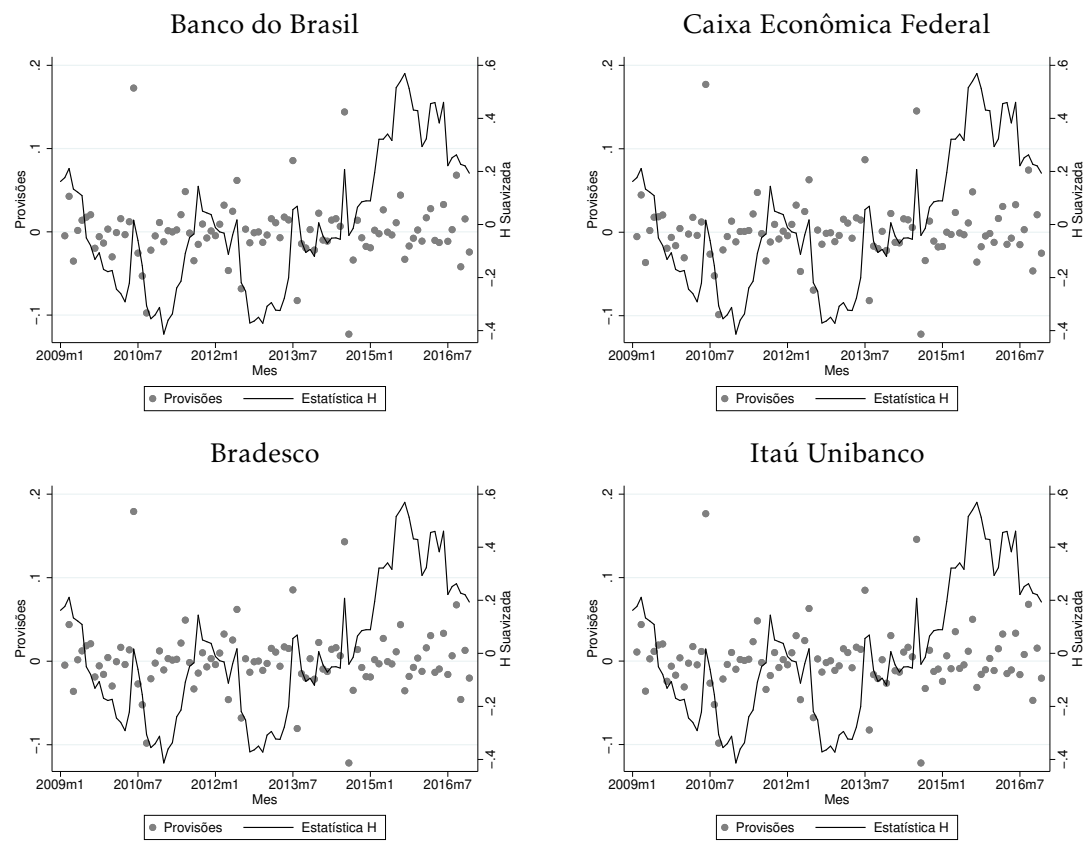

Santander

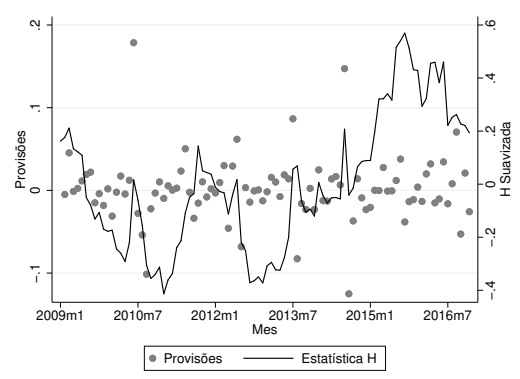

Fonte: Resultado da pesquisa 
Figura 7: Distribuição das Estatisticas H Local - Painel desbalanceado (Total de Bancos do relatório 4010 entre 2009 e 2016).

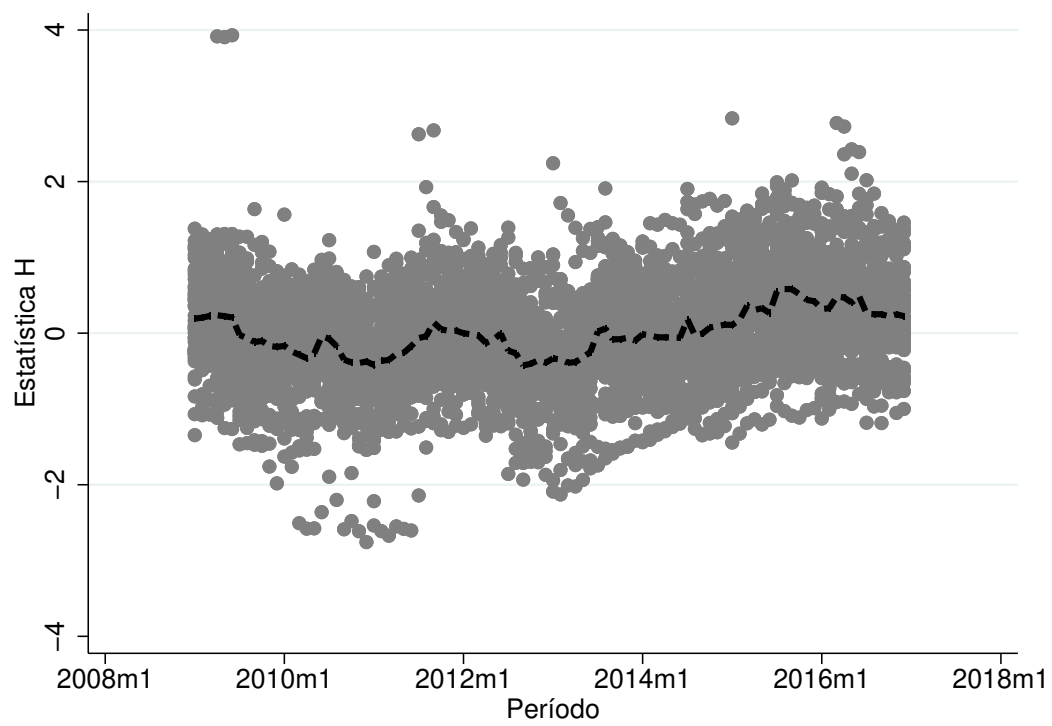

Fonte: Resultado da pesquisa.

Figura 8: Diferença entre a rentabilidade mensal da taxa Selic para as taxas praticadas nos mercados de empréstimos para pessoas físicas e para pessoas jurídicas.

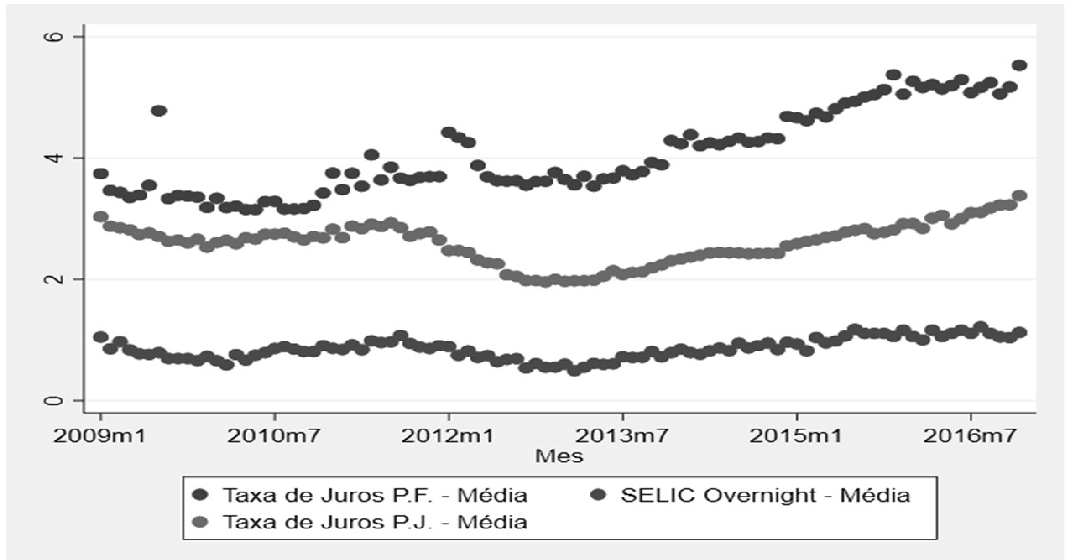

Fonte: Resultado da pesquisa.

Notas: O eixo $y$ representa o valor da taxa de juros. A taxa de juros para pessoas físicas e para pessoas jurídicas é a média das negociações ocorridas nos últimos cinco dias úteis ao fechamento de cada mês. Estas taxas são informadas por cada banco para o Banco Central do Brasil e representam a média de todas as instituições financeiras. P.F. e P.J. referem-se, respectivamente, à pessoas físicas e jurídicas. 
Tabela 16: Estimativa dos coeficientes da Estatística $\mathrm{H}$ (Efeitos fixos para 44 CNPJs)

\begin{tabular}{|c|c|c|}
\hline $\begin{array}{c}\text { Variáveis } \\
(\text { escala } \\
\text { logarítimica })\end{array}$ & $\begin{array}{c}\text { Tipo de } \\
\text { banco } 2014 \\
\text { em diante } \\
\text { Ln(RT) }\end{array}$ & $\begin{array}{c}\begin{array}{c}\text { Todo o } \\
\text { período por } \\
\text { tipo de banco }\end{array} \\
\text { Ln }(\mathrm{RT})\end{array}$ \\
\hline$\mu_{1 \_} L$ & $\begin{array}{c}0,990^{* * *} \\
(0,177)\end{array}$ & $\begin{array}{c}0,196^{* * *} \\
(0,0737)\end{array}$ \\
\hline$\mu_{1 \_} M$ & $\begin{array}{l}-1,749^{* * *} \\
(0,233)\end{array}$ & $\begin{array}{c}0,445^{* * *} \\
(0,0823)\end{array}$ \\
\hline$\mu_{1 \_} U$ & $\begin{array}{c}0,0764 \\
(0,0599)\end{array}$ & $\begin{array}{c}0,0421 \\
(0,0356)\end{array}$ \\
\hline$\mu_{2-} L$ & $\begin{array}{l}-1,642^{* * *} \\
(0,114)\end{array}$ & $\begin{array}{c}-1,152^{* * *} \\
(0,0542)\end{array}$ \\
\hline$\mu_{2}{ }_{-} M$ & $\begin{array}{l}-4,596^{* * *} \\
(0,118)\end{array}$ & $\begin{array}{l}-2,436^{* * *} \\
(0,237)\end{array}$ \\
\hline$\mu_{2} \_U$ & $\begin{array}{c}-0,133^{* *} \\
(0,0534)\end{array}$ & $\begin{array}{c}-0,0814 \\
(0,0528)\end{array}$ \\
\hline$\mu_{3 \_} L$ & $\begin{array}{c}-1,625^{* * *} \\
(0,0894)\end{array}$ & $\begin{array}{c}-0,365^{* * *} \\
(0,0583)\end{array}$ \\
\hline$\mu_{3 \_} M$ & $\begin{array}{l}-0,399^{* * *} \\
(0,130)\end{array}$ & $\begin{array}{l}-0,701^{* * *} \\
(0,108)\end{array}$ \\
\hline$\mu_{3 \_} U$ & $\begin{array}{c}0,276^{* *} \\
(0,108)\end{array}$ & $\begin{array}{c}0,436^{* * *} \\
(0,0764)\end{array}$ \\
\hline Q_ASSETS & $\begin{array}{c}0,0119 \\
(0,0268)\end{array}$ & $\begin{array}{c}-0,0319 \\
(0,0369)\end{array}$ \\
\hline L_ASSETS & $\begin{array}{c}-0,264 \\
(0,172)\end{array}$ & $\begin{array}{l}-0,534^{* * *} \\
(0,129)\end{array}$ \\
\hline PROVISÕES & $\begin{array}{c}0,555^{* * *} \\
(0,0541)\end{array}$ & $\begin{array}{c}0,584^{* * *} \\
(0,0499)\end{array}$ \\
\hline REC & $\begin{array}{c}0,0560 \\
(0,112)\end{array}$ & $\begin{array}{c}0,0732 \\
(0,0684)\end{array}$ \\
\hline MÊS & $\begin{array}{c}0,0169^{* * *} \\
(0,00353)\end{array}$ & $\begin{array}{r}0,00155^{*} \\
(0,00132)\end{array}$ \\
\hline Constante & $\begin{array}{l}8,225^{* * *} \\
(1,004)\end{array}$ & $\begin{array}{c}7,711^{* * *} \\
(0,882)\end{array}$ \\
\hline Observações & 2,492 & 6,991 \\
\hline R2 & 0,466 & 0,462 \\
\hline Qtd. CNPJ & 80 & 114 \\
\hline R2 - Within & 0,466 & 0,462 \\
\hline R2 - Overall & 0,590 & 0,721 \\
\hline R2 - Between & 0,575 & 0,781 \\
\hline
\end{tabular}

Fonte: Resultado da Pesquisa.

${ }^{* * *} \mathrm{p}<0,01,{ }^{* *} \mathrm{p}<0,05,{ }^{*} \mathrm{p}<0,1$.

Erros Padrões Robustos em parênteses. 
Tabela 17: Estatística $\mathrm{H}$ por tipo de banco e geral para o período mensal de 2014 a 2016 (114 CNPJs)

\begin{tabular}{l|r|r|r|r}
\hline Tipos de Bancos & Estatística H & Desvio Padrão & Z-Valor & $\mathbf{P}>|\mathbf{z}|$ \\
\hline Banco do Brasil & $-2,277^{* * *}$ & $(0,156)$ & $-14,61$ & 0,000 \\
Caixa Econômica Federal & $-6,744^{* * *}$ & $(0,195)$ & $-34,55$ & 0,000 \\
Bancos Privados & $0,219^{* * *}$ & $(0,121)$ & 1,82 & 0,069 \\
Todos os Bancos & $0,201^{* * *}$ & $(0,120)$ & 1,67 & 0,095 \\
\hline
\end{tabular}

Fonte: Resultado da Pesquisa.

Desvio padrão nos parênteses

$\mathrm{H} 0$ : Estatística $\mathrm{H}$ igual a zero.

${ }^{*} \mathrm{p}<0,1 ;{ }^{* *} \mathrm{p}<0,05 ;{ }^{* * *} \mathrm{p}<0,01$

Tabela 18: Equilíbrio de longo prazo (todo o período - 114 CNPJs)

\begin{tabular}{l|c|c|r|r}
\hline Tipos de Bancos & Estatística H & Desvio Padrão & Z-Valor & $\mathbf{P}>\mathbf{z} \mid$ \\
\hline Banco do Brasil & $-0,793^{* * *}$ & $(0,055)$ & $-14,45$ & 0,000 \\
Caixa Econômica Federal & $-2,919^{* * *}$ & $(0,346)$ & $-8,44$ & 0,000 \\
Bancos Privados & 0,0630 & $(0,133)$ & $-0,48$ & 0,632 \\
Todos os Bancos & 0,0063 & $(0,118)$ & 0,05 & 0,957 \\
\hline
\end{tabular}

Fonte: Resultado da Pesquisa.

Desvio padrão nos parênteses

H0: Estatística H igual a zero.

${ }^{*} \mathrm{p}<0,1 ;{ }^{* *} \mathrm{p}<0,05 ;{ }^{* * *} \mathrm{p}<0,01$

Tabela 19: Equilíbrio de longo prazo (2014 em diante - 114 CNPJs)

\begin{tabular}{l|c|c|c|c}
\hline Tipos de Bancos & Estatística $\mathbf{H}$ & Desvio Padrão & $\mathbf{Z}-$ Valor & $\mathbf{P}>|\mathbf{z}|$ \\
\hline Banco do Brasil & $-0,033$ & $(0,222)$ & $-0,15$ & 0,881 \\
Caixa Econômica Federal & $-4,185$ & $(0,127)$ & 33,04 & 0,000 \\
Bancos Privados & $-0,088$ & 1,777 & $-0,49$ & 0,621 \\
Todos os Bancos & $-0,015$ & $(0,146)$ & 0,10 & 0,919 \\
\hline
\end{tabular}

Fonte: Resultado da Pesquisa.

Desvio padrão nos parênteses

H0: Estatística H igual a zero.

${ }^{*} \mathrm{p}<0,1$; ${ }^{* *} \mathrm{p}<0,05$; ${ }^{* * *} \mathrm{p}<0,01$ 
Tabela 20: Regressões para o Cálculo da Estatística H Local (Efeitos Fixos por Mês - 44 CNPJs).

\begin{tabular}{|c|c|c|c|c|c|}
\hline $\begin{array}{c}\text { Variáveis } \\
\text { (escala } \\
\text { logarítimica) }\end{array}$ & $\ln (\mathrm{RT})$ & $\ln \left(\omega_{1}\right)$ & $\ln \left(\omega_{2}\right)$ & $\ln \left(\omega_{3}\right)$ & RT resid \\
\hline Q_ASSETS & $\begin{array}{c}0,0443^{* * *} \\
(0,00551)\end{array}$ & $\begin{array}{c}0,0352^{* * *} \\
(0,00310)\end{array}$ & $\begin{array}{l}-0,294^{* * *} \\
(0,00463)\end{array}$ & $\begin{array}{c}0,0600^{* * *} \\
(0,00196)\end{array}$ & \\
\hline L_ASSETS & $\begin{array}{c}-1,086^{* * *} \\
(0,0208)\end{array}$ & $\begin{array}{c}-0,191^{* * *} \\
(0,0117)\end{array}$ & $\begin{array}{c}0,583^{* * *} \\
(0,00949)\end{array}$ & $\begin{array}{c}-0,191^{* * *} \\
(0,0168)\end{array}$ & \\
\hline Provisões & $\begin{array}{c}0,630^{* * *} \\
(0,00758)\end{array}$ & $\begin{array}{c}0,0232^{* * *} \\
(0,00326)\end{array}$ & $\begin{array}{c}-0,0809^{* * *} \\
(0,00545)\end{array}$ & $\begin{array}{c}-0,0941^{* * *} \\
(0,00285)\end{array}$ & \\
\hline REC & $\begin{array}{r}0,00697 \\
(0,0186)\end{array}$ & $\begin{array}{c}0,267^{* * *} \\
(0,0175)\end{array}$ & $\begin{array}{c}-0,344^{* * *} \\
(0,0154)\end{array}$ & $\begin{array}{c}0,0205^{*} \\
(0,0121)\end{array}$ & \\
\hline$\omega 1_{\text {resid }}$ & & & & & $\begin{array}{r}0,341^{* * *} \\
(0,00520)\end{array}$ \\
\hline$\omega 2_{\text {resid }}$ & & & & & $\begin{array}{l}-0,0118 \\
(0,00834)\end{array}$ \\
\hline$\omega 3_{\text {resid }}$ & & & & & $\begin{array}{c}0,737^{* * *} \\
(0,0137)\end{array}$ \\
\hline Constante & $\begin{array}{c}6,383^{* * *} \\
(0,189) \\
\end{array}$ & $\begin{array}{c}-0,741^{* * *} \\
(0,0763) \\
\end{array}$ & $\begin{array}{c}1,303^{* * *} \\
(0,137) \\
\end{array}$ & $\begin{array}{c}1,653^{* * *} \\
(0,0881) \\
\end{array}$ & $-2,19 \mathrm{e}-10$ \\
\hline Observações & 4,170 & 4,170 & 4,170 & 4,170 & 4,170 \\
\hline R2 & 0,798 & 0,043 & 0,448 & 0,189 & 0,345 \\
\hline Meses & 96 & 96 & 96 & 96 & 96 \\
\hline R2 Within & 0,798 & 0,0426 & 0,448 & 0,189 & 0,345 \\
\hline R2 Overall & 0,768 & 0,0527 & 0,435 & 0,163 & 0,269 \\
\hline R2 Between & 0,711 & 0,538 & 0,129 & 0,00593 & 0,108 \\
\hline
\end{tabular}

Fonte: Resultado da Pesquisa.

Erros Padrões Robustos em Parênteses

$\mathrm{H} 0$ : Estatística $\mathrm{H}$ igual a zero.

${ }^{*} \mathrm{p}<0,1 ;{ }^{* *} \mathrm{p}<0,05 ;{ }^{* * *} \mathrm{p}<0,01$ 
Tabela 21: Regressões para o Cálculo da Estatística H Local (Efeitos Fixos por Mês - 114 CNPJs).

\begin{tabular}{|c|c|c|c|c|c|}
\hline $\begin{array}{c}\text { Variáveis } \\
\text { (escala } \\
\text { logarítimica) }\end{array}$ & $\ln (\mathrm{RT})$ & $\ln \left(\omega_{1}\right)$ & $\ln \left(\omega_{2}\right)$ & $\ln \left(\omega_{3}\right)$ & RT resid \\
\hline Q_ASSETS & $0,0369^{* * *}$ & $0,0331^{* * *}$ & $-0,272^{* * *}$ & $0,0103^{* * *}$ & \\
\hline$L \_A S S E T S$ & $\begin{array}{c}(0,00350) \\
-0,813^{* * *} \\
(0,0229)\end{array}$ & $\begin{array}{c}(0,00360) \\
-0,137^{* * *} \\
(0,0114)\end{array}$ & $\begin{array}{c}(0,00399) \\
0,400^{* * *} \\
(0,0135)\end{array}$ & $\begin{array}{c}(0,00206) \\
0,0442^{* * *} \\
(0,0154)\end{array}$ & \\
\hline Provisões & $\begin{array}{c}0,619^{* * *} \\
(0,00499)\end{array}$ & $\begin{array}{c}0,0672^{* * *} \\
(0,00326)\end{array}$ & $\begin{array}{l}-0,112^{* * *} \\
(0,00330)\end{array}$ & $\begin{array}{c}-0,0352^{* * *} \\
(0,00241)\end{array}$ & \\
\hline REC & $\begin{array}{c}0,0226 \\
(0,0218)\end{array}$ & $\begin{array}{c}0,248^{* * *} \\
(0,0167)\end{array}$ & $\begin{array}{c}-0,292^{* * *} \\
(0,0195)\end{array}$ & $\begin{array}{c}-0,155^{* * *} \\
(0,0112)\end{array}$ & \\
\hline$\omega 1_{\text {resid }}$ & & & & & $\begin{array}{c}0,240^{* * *} \\
(0,0163)\end{array}$ \\
\hline$\omega 2_{\text {resid }}$ & & & & & $\begin{array}{c}-0,152^{* * *} \\
(0,0100)\end{array}$ \\
\hline$\omega 3_{\text {resid }}$ & & & & & $\begin{array}{c}0,808^{* * *} \\
(0,0151)\end{array}$ \\
\hline Constante & $\begin{array}{l}6,945^{* * *} \\
(0,156)\end{array}$ & $\begin{array}{c}-1,211^{* * *} \\
(0,0807)\end{array}$ & $\begin{array}{c}1,034^{* * *} \\
(0,0926)\end{array}$ & $\begin{array}{c}1,192^{* * *} \\
(0,0708) \\
\end{array}$ & $\begin{array}{c}0,0751^{* * *} \\
(0,000523)\end{array}$ \\
\hline Observações & 7,527 & 6,991 & 7,527 & 7,527 & 6,991 \\
\hline R2 & 0,656 & 0,067 & 0,394 & 0,065 & 0,346 \\
\hline Meses & 96 & 96 & 96 & 96 & 96 \\
\hline R2 Within & 0,656 & 0,0671 & 0,394 & 0,0652 & 0,346 \\
\hline R2 Overall & 0,654 & 0,0672 & 0,391 & 0,0497 & 0,257 \\
\hline R2 Between & 0,702 & 0,0761 & 0,141 & 0,118 & 0,00478 \\
\hline
\end{tabular}

Fonte: Resultado da Pesquisa.

Desvio padrão nos parênteses.

H0: Estatística H igual a zero.

${ }^{*} \mathrm{p}<0,1 ;{ }^{* *} \mathrm{p}<0,05 ;{ }^{* * *} \mathrm{p}<0,01$

Tabela 22: Teste de Cointegração entre a Estatística H e as Reservas Técnicas

\begin{tabular}{lcccccc}
\hline Bancos & Máx rank Parm & LL & Autovalor & Traço & Valor crítico 1\% \\
\hline \multirow{2}{*}{ Banco do Brasil } & 0 & 6 & $-7,560$ & - & 26,573 & 20,040 \\
& 1 & 9 & 4,667 & 0,229 & $2,1186^{*}$ & 6,650 \\
\hline \multirow{2}{*}{ Caixa Econômica Federal } & 0 & 6 & $-7,443$ & - & 25,910 & 20,040 \\
& 1 & 9 & 4,365 & 0,222 & $2,2929^{*}$ & 6,650 \\
\hline \multirow{2}{*}{ Bradesco } & 0 & 6 & $-8,059$ & - & 26,771 & 20,040 \\
& 1 & 9 & 4,268 & 0,231 & $2,1175^{*}$ & 6,650 \\
\hline \multirow{2}{*}{ Itaú-Unibanco } & 0 & 6 & $-7,873$ & - & 27,696 & 20,040 \\
\hline \multirow{2}{*}{ Santander } & 1 & 9 & 4,967 & 0,239 & $2,0165^{*}$ & 6,650 \\
\hline Fonte: Resultad & 0 & 6 & $-8,006$ & - & 28,424 & 20,040 \\
\end{tabular}

Fonte: Resultado da Pesquisa. 
